NBSIR 78-883

\title{
ATMOSPHERIC PROPAGATION EQUATIONS USED IN THE NBS EARTH TERMINAL MEASUREMENT SYSTEM
}

W. C. Daywitt

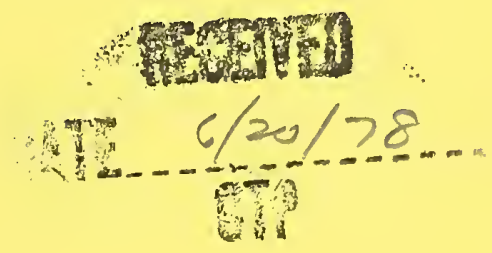

Electromagnetics Division

Institute for Basic Standards

National Bureau of Standards

Boulder, Colorado 80303

April 1978 



\section{NBSIR 78-883}

\section{ATMOSPHERIC PROPAGATION EQUATIONS USED IN THE NBS EARTH TERMINAL MEASUREMENT SYSTEM}

W. C. Daywitt

Electromagnetics Division Institute for Basic Standards

National Bureau of Standards

Boulder, Colorado 80303

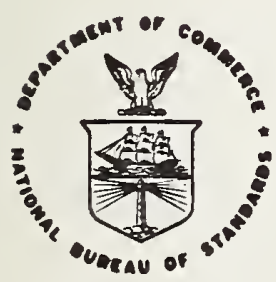

U.S. DEPARTMENT OF COMMERCE, Juanita M. Kreps, Secretary Sidney Harman, Under Secretary Jordan J. Baruch, Assistant Secretary for Science and Technology 

LIST OF FIGURES AND TABLES. . . . . . . . . . . . . . . . . . . iv ABSTRACT. . . . . . . . . . . . . . . . . . . . 1

1. INTRODUCTION. . . . . . . . . . . . . . . . . . . . . 1

2. AN APPROXIMATE RAY-BENDING EQUATION • . . . . . . . . . . . . 2

2.1 Refraction-Angle Error . . . . . . . . . . . . . . . 7

2.1.1 Nonintegral Approximation. . . . . . . . . . . 7

2.1.2 Nonspherical Symmetry. . . . . . . . . . . 7

2.1.3 Refractivity Constants . . . . . . . . . 9 9

2.1.4 Temperature, Pressure, and Water-Vapor Density Profiles . . . . . . . . . . 10

2.1.5 Total Refraction-Angle Error . . . . . . . . . 10

3. ATMOSPHERIC PROFILE MODELS. . . . . . . . . . . . . . . 10

4. AN APPROXIMATE TRANSMISSION-COEFFICIENT EQUATION. . . . . . . . . . 11

4.1 Transmission-Coefficient Errors. . . . . . . . . . . . 14

4.1.1 Nonintegral Approximation. . . . . . . . 15

4.1.2 Nonspherical Symmetry. . . . . . . . . 15

4.1.3 Absorption-Coefficient Constants . . . . . . 15

4.1.4 Temperature, Pressure, and Water-Vapor Density Profiles.............. 15

4.1.5 Total Transmission-Coefficient Error . . . . . . 16

5. RESULTS AND CONCLUSIONS . . . . . . . . . . . . . . . . 16

6. ACKNOWLEDGMENTS . . . . . . . . . . . . . . . . . 17

7. REFERENCES. . . . . . . . . . . . . . . . . 18 
Figure 1.

Figure 2.

Figure 3.

Figure 4. Figure 5. Figure 6.

Figure 7.

Figure 8.

Figure 9.

Figure 10.

Figure 11.

Figure 12.

Figure 13.

Figure 14.

Figure 15.

Figure 16.

Figure 17 .
Geometrical idealization of the earth's atmosphere. World maps of the mean sea-level dry term $D_{0}$ and wet term $W_{0}$ for
May (from Bean, et al. [7]).

Truncated refraction angle and truncation error versus truncation altitutde at a $3^{\circ}$ elevation angle.

Average May refraction angle for Washington, D.C.

Systematic error components for the refraction angle.

Geometrical idealization of the earth's atmosphere showing that portion (shaded) in the vicinity of the observer of interest in determining ray bending.

Average May refractivity profile for Washington, D.C., showing that "area" in which the real profile is assumed to lie.

A portion of the 1962 U.S. standard temperature profile showing that "area" in which the real profile is assumed to lie.

Total systematic refraction-angle error.

A portion of the 1962 U.S. standard atmospheric temperature profile showing the three approximations (dashed curves) used in the text.

A portion of the 1962 standard pressure profile showing the two approximations (dashed curves) used in the text.

A portion of the 1962 U.S. standard water-vapor density profile showing the two approximations (dashed curves) used in the text.

Molecular oxygen and water-vapor absorption coefficients versus frequency (for 293 kelvins, 1013.25 millibars, and $7.75 \mathrm{~g} / \mathrm{m}^{3}$ ).

Zenith attenuation due to molecular oxygen and water vapor versus frequency (for 300 kelvins, 1013.25 millibars, and $7.75 \mathrm{~g} / \mathrm{m}^{3}$ ).

Truncated zenith attenuation and truncation error versus truncation altitude (at $10 \mathrm{GHz}$ for Washington, D.C., in May).

Systematic error components for the transmission coefficient (at $10 \mathrm{GHz}$ for Washington, D.C., in May).

Total systematic transmission-coefficient error (at $10 \mathrm{GHz}$ for Washington, D.C., in May). 
Table 1. Refraction-angle errors between various approximations and the "exact" model (for Washington, D.C., in May).

Table 2. Approximate refraction-angle equations used in the Earth Terminal Measurement System.

Table 3. Approximate transmission-coefficient equations used in the Earth Terminal Measurement System. 

W. C. Daywitt

\begin{abstract}
A derivation of equations for approximating the atmospheric refraction angle and transmission coefficient is outlined. The approximations apply in the $1 \mathrm{GHz}$ to $10 \mathrm{GHz}$ frequency range and are accompanied by systematic error estimates. They are used in the NBS Earth Terminal Measurement System for quasi-real-time calculations concerned with the measurement of earth-terminal gain-to-noise-temperature ratio (G/T), satellite effective isotropic radiated power (EIRP), and downlink carrier-to-noise-density ratio $(\mathrm{C} / \mathrm{kT})$.
\end{abstract}

Key Words: Atmosphere; downlink carrier-to-noise-density ratio (C/kT); satellite effective isotropic radiated power (EIRP); error analysis; earth-terminal gain-to-noise-temperature ratio (G/T); refraction angle; satellite communications; transmission coefficient.

\title{
1. INTRODUCTION
}

The Electromagnetics Division of the National Bureau of Standards has contructed an Earth Terminal Measurement System (ETMS) designed to determine earth terminal $\mathrm{G} / \mathrm{T}$, downlink $\mathrm{C} / \mathrm{kT}$, and satellite $\mathrm{EIRP}$ in the $1 \mathrm{GHz}$ to $10 \mathrm{GHz}$ frequency range using a calibrated radio star [1]. The system operates off the i-f patch panel of the downlink earth terminal, automatically controlling the several measurement sequences needed to determine these parameters. In addition to the programmed sequences, the ETMS contains working equations [2,3] for calculating $\mathrm{G} / \mathrm{T}, \mathrm{C} / \mathrm{kT}$, and EIRP from measurement data and for calculating the associated errors on a quasi-real-time basis. The determination of G/T and EIRP requires that the effects of the atmosphere on the radio-star flux density and on the satellite signal be removed from the measurement data by estimating the atmospheric transmission coefficient at the time the measurement is performed. The ray bending caused by atmospheric refraction is also estimated for correct pointing of the earth-terminal antenna during the measurements. The working equations derived for these estimates and their corresponding errors are the subject of this report.

A vast amount of effort has been and still is being expanded in the field of atmospheric studies [4]. Unfortunately, few results of these studies are tailored to the specific needs of the ETMS. For instance, computer programs like the Longley-Rice program [5] for calculating atmospheric loss are far too large and time consuming for the ETMS to handle, while some of the simple 
ray-bending expressions available in the literature [6] are accompanied by insufficient information for an evaluation of the systematic errors involved. The primary ETMS need is for simple expressions, capable of being performed on a quasi-real-time basis, to estimate atmospheric ray bending and transmission and their associated errors.

The transmission equations account for absorption by molecular oxygen and water vapor and were derived principally for the $1 \mathrm{GHz}$ to $10 \mathrm{GHz}$ frequency region. Tropospheric scattering loss and the effective loss caused by refractive spreading of the signal wavefront will not be discussed--nor will effects due to scintillation or multipath fading. Furthermore, since measurement accuracy is of utmost importance and is maximized by performing measurements in clear, stable weather only, the effects of inclement weather will be ignored.

The atmospheric models used in deriving the following equations will be discussed when needed. Generally speaking, however, the models were chosen for simplicity and amenability to simple calculations and interpretation, while still producing reasonably accurate estimates. Comparison of the results derived from these models with more or less sophisticated calculations shows good agreement.

The approximate equations derived for refractive ray bending will be discussed first along with the assumed atmospheric refractivity model, followed by a discussion of the reasoning leading to the corresponding error estimates. Next, the atmospheric model assumed in the transmission-coefficient derivation will be presented, followed by the corresponding equations and error estimates. Although many of the calculations are performed using data specific to the Washington, D.C., area, the results apply to a much wider geographical scale.

\section{AN APPROXIMATE RAY-BENDING EQUATION}

Earth-terminal measurements using a calibrated radio star as performed by the ETMS [2] require earth-terminal antenna pointing angles calculated on a quasi-real-time basis with an error of 3 arcminutes or less. Part of this calculation includes an estimate of the apparent position of the radio star, whose difference from the true position is caused by refractive bending of the principal rays from the star as they pass through the atmosphere to the antenna. A derivation of a simplified equation for this difference, called the refraction angle, is reviewed in this section. As will be seen, the correction and its error are both functions of the star's elevation above the horizon. 
Figure 1 is a cross-sectional view of the earth showing the relationship of an observer at altitude $Z$ above sea level to the refraction angle $\tau$. $R$ is the average sea-level radius of the earth with $z$ representing an arbitrary height above the observer's altitude. $n_{z}$ and $n$ represent the atmospheric refractive index at heights $z$ and $z$ respectively. The index of refraction is assumed to be unity above some fictitious height labeled here as the "atmospheric ceiling," above which no significant ray bending takes place. $\theta$ is the angle between the perpendicular-to-the-radius vector from the center of the earth to the point on the tangent to the ray at altitude $z, \theta_{Z}$ and $\theta_{T}$ represent respectively the elevation angles for the apparent and true positions of the radio star or satellite. That is, a principal ray entering the atmosphere at an elevation angle $\theta_{T}$ has an arrival angle at the observer equal to $\theta_{\mathrm{Z}}$. Thus, the refraction angle $\tau$ is related to $\theta_{Z}$ and $\theta_{T}$ by the equation

$$
\tau=\theta_{Z}{ }^{-\theta} T
$$

For a given angle $\theta_{T}$, $\tau$ varies with atmospheric conditions, requiring that the index of refraction be known at each point on the ray path if an accurate calculation of the refraction angle is to be performed. Unfortunately, such complete information is never available, and various approximations for $\tau$ must be made.

By assuming a spherically symmetric or stratified atmosphere, the refraction angle can be calculated from the equation [6]

$$
\tau=-\int_{\mathrm{n}_{Z}}^{1} \frac{\operatorname{ctn} \theta}{\mathrm{n}} \mathrm{dn}
$$

where $\operatorname{ctn} \theta$ is the $\operatorname{cotangent}$ of the angle $\theta$ appearing in figure 1 . The integral is performed along the ray path, but is too time consuming when performed by the ETMS to be useful in quasi-real-time. The cotangent can be related to other parameters appearing in figure 1 through the equation

$$
\left.\operatorname{ctn} \theta=\left(\frac{n r}{n_{Z}(R+Z) \operatorname{Cos} \theta_{Z}}\right)^{2}-1\right)^{-1 / 2} .
$$

The index of refraction is related to the atmospheric refractivity $N$ through the equation 


$$
\mathrm{n}=1+\mathrm{N} / 10^{6}
$$

The assumption of spherical symmetry implies that both $\mathrm{n}$ and $\mathrm{N}$ are functions of $z$ only. To complete an atmospheric model for calculating $\tau$, a functional form for $\mathrm{N}$ versus altitude must be assumed.

Of the different models that could be chosen for $N$, the following biexponential model was selected $[6,7]$

$$
N(z)=\left\{\begin{array}{l}
D(z) e^{-(z-Z) / H_{1}}+W(Z) e^{-(z-Z) / H w}, z \leq Z_{t} \\
D(Z) e^{-Z_{t} / H_{l}} e^{-\left(z-Z_{t}\right) / H_{2}}+W(Z) e^{-(z-Z) / H w}, z>Z_{t}
\end{array}\right.
$$

$D(Z)$ is the refractivity of the "dry" constituents of the atmosphere at the observer's altitude $Z$, and $W(Z)$ is the corresponding "wet" refractivity accounting for the presence of water vapor. $\mathrm{H}_{1}$ and $\mathrm{H}_{2}$ are "dry" and "wet" scale heights applicable respectively below and above the transition altitude $z_{t}$ separating tropospheric and stratospheric exponential behaviors. Hw is a "wet" term scale height. The "dry" and "wet" refractivities are expressible in terms of measurable atmospheric variables at the observer's altitude through the eqs $[6]$.

$$
\begin{aligned}
& D(Z)=\frac{77.6 \mathrm{P}(Z)}{T(Z)} \\
& W(Z)=\frac{3.73 \times 10^{5} \mathrm{e}(\mathrm{z})}{\mathrm{T}^{2}(Z)} .
\end{aligned}
$$

$\mathrm{P}(\mathrm{Z})$ is the total atmospheric pressure in millibars, $\mathrm{T}(\mathrm{Z})$ is the atmospheric temperature in kelvins, and $\mathrm{e}(\mathrm{Z})$ is the water-vapor pressure in millibars. Although there is a considerable amount of average data [7] available for the parameters appearing in eqs (2.5), there are no equations available for determining $\mathrm{H}_{1}, \mathrm{H}_{2}$, $\mathrm{Hw}$, or $\mathrm{Z}_{t}$ from measurements of ground-level atmospheric variables themselves. Fortunately, these latter parameters are not needed in some of the nonintegral approximations of eq $(2.2)$ to be discussed.

To eliminate the integral in eq (2.2) and reduce the calculation of $\tau$ to a simple equation that can be handled by the ETMS in quasi-real-time, a number of nonintegral approximations to eq (2.2) were examined, the one yielding the least error when compared to eq (2.2) to be used by the ETMS. The "exact" calculation 
performed according to eq (2.2) employs the following average data appropriate to average May weather conditıons in Washington, D.C.:

$$
\begin{array}{lll}
\mathrm{D}(0)=273 & , & \mathrm{~W}(0)=60 \\
\mathrm{H}_{\mathrm{I}}=9.5 \mathrm{~km} & , & \mathrm{H}_{2}=6.2 \mathrm{~km} \\
\mathrm{HW}=2.6 \mathrm{~km} & , & \mathrm{Z}_{\mathrm{t}}=11.4 \mathrm{~km} \\
\mathrm{Z} \equiv 0 \mathrm{~km} & , & \mathrm{~N}=\mathrm{D}(0)+W(0)
\end{array}
$$

The first six entries in the table were obtained from global maps [7] of the parameters involved, two of which are reproduced in figure 2. The circled dot represents the location of Washington, D.C. Before proceeding to the approximations, it is worthwhile to examine the effect of truncating the upper limit of the integral in eq $(2.2)$.

In evaluating the integral of eq (2.2), the limits on the integral sign are transformed from " $\mathrm{n}_{\mathrm{z}}$ to $\mathrm{n}$," to " $\mathrm{z}$ to infinity" respectively, raising the question of where to truncate the upper limit. Figure 3 shows the effect of truncating at various altitudes. : The upper curve is the refraction angle as calculated by eq (2.2) for an apparent elevation angle of $3^{\circ}$ as a function of the altitude at which the upper limit is truncated. The lower curve gives the corresponding truncation error, indicating an error less than 0.025 minutes for an altitude of $40 \mathrm{~km}$ or greater. Using figure 3 as a guide, an upper limit of $60 \mathrm{~km}$ was chosen for the "exact" calculation using eq (2.2), yielding an error of less than 0.001 minutes. The resulting refraction angle $\tau$ (as a function of apparent elevation angle) using the data given in the preceding table is shown in figure 4. This curve is the "standard" against which the following approximations to eq (2.2) were judged.

The results of six refraction angle approximations were compared to the "exact" results. These six approximations are summarized in column 1 of table 1 and consist of: (1) a "flat-earth approximation; (2) and (3) zero and firstorder expansions of the eq (2.2) integral in powers of $z /(R+Z)$ (see fig 1 and eq (2.3)); (4) a $\csc ^{2} \theta_{Z}$ fit to the "exact" data at $2^{\circ}$ and $20^{\circ}$ elevation angles leading to the two coefficients appearing in the fifth equation; (5) a $\operatorname{ctn}^{2} \theta_{Z}$ fit at $2^{\circ}$ and $20^{\circ}$; and (6) an equation to be discussed later that evolved from the $\operatorname{ctn}^{2} \theta_{z}$ fit.

The "flat-earth" approximation results from letting $\mathrm{R}$ in eq (2.3) increase without limit (note that $\mathrm{r}=\mathrm{R}+\mathrm{Z}+\mathrm{z}$ ), yielding an integral in eq (2.2) that is integrable in closed form. The resulting approximation is found in the first 
row and column of table 1. The remaining columns in the first row show the difference between this approximation and the "exact" calculation. For example, the approximate estimate of $\tau$ is $5.83^{\prime}$ greater than the "exact" estimate at a $3^{\circ}$ elevation angle.

The next two approximations, numbers 2 and 3, are expansions in powers of $\mathrm{z} /(\mathrm{R}+\mathrm{Z})$ (after $\mathrm{n}$ and $\mathrm{n}_{\mathrm{Z}}$ are discarded from eqs (2.2) and (2.3)) whose coefficients are functions of the parameters appearing in eq (2.5). The particular values of these coefficients appearing in the table were calculated from the preceding data table.

As previously mentioned, the coefficients of the fourth and fifth approximations in table 1 were determined by fitting these equations with undetermined coefficients to the "exact" results at $2^{\circ}$ and $20^{\circ}$ elevation angles. With the coefficients in the fifth equation determined in this manner for a number of other locations and months using maps like those appearing in figure 2, the coefficient of the $\operatorname{ctn}^{2} \theta_{Z}$ term was found to be remarkably similar for the various locations and months of the year, the average being -0.0131 . With this fact in mind, an equation of the form given in the outer bracket of the sixth equation in column 1 was compared to the "exact" calculation for the various locations and months previously mentioned and was found to be systematically $3.2 \%$ below the "exact" calculations. With this $3.2 \%$ taken into account, the sixth equation resulted.

Examination of the errors in table 1 shows the last three approximations to be considerably superior to the first three at low elevation angles. However, the fourth and fifth approximations are determined by curve fitting to the "exact" calculation and are therefore not useful for quasi-real-time calculations. Therefore, the sixth approximation was used to calculate the refraction angle $\tau$.

The sixth equation of table 1 as it is rewritten in eq (2T1)* of table 2 is used by the ETMS to determine the refraction angle $\tau$. The refractivity, $N(Z)=D(Z)+W(Z)$, given by eq $(2 T 2)$ is derived from eqs (2.6) by using an atmospheric model described later. The saturated water-vapor pressure e (eq 2T4) is a least squares fit to the temperature/saturated water-vapor pressure curve [8]. Equation (2T6) will be explained later.

*Equation designations containing the letter $\mathrm{T}$ refer to equations found in the tables at the end of the report. 


\subsection{Refraction-Angle Error}

An estimate of the systematic error associated with using the refractionangle eq (2T1) to calculate refraction angles in the real atmosphere will be reviewed in this section. The total error is comprised of components arising from several sources: (1) use of the nonintegral approximation eq (2T1) in place of eq (2.2); (2) assumption of a spherically symmetric atmosphere; (3) uncertainties in the constants appearing in eqs $(2.6)$; (4) uncertainties in atmospheric temperature profile; (5) uncertainties in atmospheric pressure profile; (6) uncertainties in atmospheric water-vapor density profile; and (7) uncertainties in the observer's altitude above sea level.

\subsubsection{Nonintegral Approximation}

Errors in calculating the refraction angle by using the approximate eq (2T1) in place of eq (2.2) were obtained in section 2 while deriving eq (2T1) and are presented in row 6 of table 1 . The same process that generated these errors was repeated for a number of other areas around the globe with no radical departures from those errors given in the table for the Washington, D.C., area. Therefore, the magnitude of the errors in row 6 was taken as "the" refraction-angle error. Curve number 1 of figure 5 is a graph of this error as a function of apparent elevation angle. Although not shown on the graph, the error increases quite rapidly for elevation angles less than $3^{\circ}$; and therefore the range of applicability for eq (2T1) is limited to elevation angles greater than this value. For most earth terminals this limitation poses no problem.

\subsubsection{Nonspherical Symmetry}

The assumption of a spherically symmetric or stratified atmosphere was essential to the derivation of eq (2T1). The fact that the real atmosphere differs from this model leads to an error when using eq (2T1) to estimate $\tau$. With reference to figure 1 , this assumption implies that the refractivity $N$ at the point on the ray path with radius $r$ is identical with the value of $N(Z)$ given by eq (2.5) directly above the observer's head. With reference to figure 6 , it assumes that the refractivity has equal values at points 1,2 , or 
3 , in fact at any point around the globe with radius $R+Z+z$. An estimate of the error caused by variation of $\mathrm{N}$ between points 1 and 2 of figure 6 is discussed in this subsection.

The shaded portion of the atmosphere in figure 6 represents that angular extent $\dot{\phi}$ of the atmosphere responsible for bending the ray shown, and therefore the area through which the horizontal variation of $\mathrm{N}$ should be assessed. For elevation angles $\theta_{\mathrm{Z}}$ greater than $2^{\circ}$, $\phi$ can be approximated by the equation

$$
\phi=\operatorname{Cos}^{-1}\left(\frac{\operatorname{Cos} \theta z}{1+h / R}\right)-\theta_{Z}
$$

where $\mathrm{h}$ is the altitude of the "atmospheric ceiling" and $\mathrm{R}$ is the average radius of the earth. Figure 3 can be used to show that (for $\theta_{z}=3^{\circ}$ ) $98 \%$ of the ray bending is accounted for with h equal to $25 \mathrm{~km}$.

Using this value for $h$ and $6400 \mathrm{~km}$ for $\mathrm{R}$, the $\phi$ calculated from eq (2.7) represents an upper limit to that angular extent of the atmosphere to be considered in estimating the variation of $\mathrm{N}$ for a given $\theta_{\mathrm{Z}}$. As explained in the next paragraph, eq (2.7) will be used with the maps in figure 2 to estimate upper and lower bounds to the average variation of the refractivity along the ray path shown in figure 6.

To predict the error in using eq (2T1) to estimate $\tau$, the first term is sufficient. Use of this equation implies the functional variation for $N(z)$ given by eq (2.5) and shown as the solid curve in figure 7. The area between the dashed curves in this figure is assumed to contain the real refractivity variation along the ray path shown in figure 6 even though the real variation may not follow the central curve. The vertical separation between the dashed curves was determined by using eq (2.7) in the following manner. With $\theta_{Z}$ equal to $2^{\circ}$, eq $(2.7)$ predicts an angle $\phi$ equal to $3.4^{\circ}$ which can be translated into a longitude-latitude ellipse around the point shown on the $D_{0}$ and $W_{0}$ maps of figure 2. Using the diameter of these ellipses in the direction of maximum $\mathrm{N}$ variation (perpendicular to the contour lines) in the two maps leads to a value for $\mathrm{N}_{\mathrm{O}}\left(\mathrm{N}_{\mathrm{O}}=\mathrm{D}_{\mathrm{O}}+\mathrm{W}_{\mathrm{O}}\right)$ of $333 \pm 18(5.4 \%)$. The dashed curves in figure 7 were taken to be the central curve $\pm 5.4 \%$, and when used to calculate $\tau$ represent maximum and minimum limits to the value of $\tau$ for any real refractivity curve within their boundaries. 
For extraterrestrial radio sources at the observer's zenith, the refraction angle vanishes no matter what the refractivity profile. Therefore, as $\theta_{Z}$ approaches $90^{\circ}$, the error in predicting $\tau$ must also vanish. Correspondingly, the error in $\tau$ due to nonspherical symmetry is assumed proportional to $\phi$ of eq (2.7). The resulting error is shown as curve number 2 in figure 5 .

\subsubsection{Refractivity Constants}

The constants $\left(77.6\right.$ and $3.73 \times 10^{5}$ ) appearing in eq (2.6) for $D(Z)$ and $W(Z)$ are uncertain by the amounts $0.2 \%$ and $0.9 \%$ respectively [6]. The resulting refraction-angle error calculated from the first term of eq (2T1) is shown as curve number 3 in figure 5.

\subsubsection{Temperature, Pressure, and Water-Vapor Density Profiles}

The refraction-angle error caused by horizontal gradients in the atmospheric variables leading to the refractivity has already been accounted for in subsection 2.1.2. Nothing has yet been done, however, to estimate the error caused by uncertainty in the vertical $\mathrm{N}$ profile (eq 2.5) itself. The error will be estimated in this subsection by assuming uncertainties for the temperature, pressure, and water-vapor density profiles that lead to the $\mathrm{N}$ profile predicted by eqs $(2.6)$.

Atmospheric models assumed for vertical temperature, pressure, and watervapor density variations will be discussed later. However, the first $15 \mathrm{~km}$ portion of the temperature profile model is shown in figure 8 as the solid curve, shifted in the vertical direction according to the measured gound-level temperature. The dashed curves correspond to the solid curve \pm 10 kelvins. The real temperature profile with the same ground-level temperature as the model is assumed to lie between the dashed curves. When used to calculate the refraction angle, the dashed curves then represent lower and upper bounds to the calculation, one-half the difference of which is taken to be the refraction-angle error due to uncertainties in the temperature profile. This resulting error is plotted as curve number 4 in tigure 5 .

With reference to the preceding discussion, the refraction-angle error due to uncertainties in the vertical atmospheric-pressure profile was calculated in a similar fashion through the use of eq (2T1), eq (2T2), and a pressure profile 
model discussed later. It is assumed that the real profile is contained within bounds established by curves corresponding to the model profile \pm 10 millibars. The resulting error as a function of elevation angle is shown as curve number 5 in figure 5 .

The water-vapor density is determined at the observer's altitude by measuring the atmospheric temperature and relative humidity, and by using eqs (2T4) and (2T3) to calculate the water-vapor density. The resulting value is taken as the starting point for a vertical water-vapor density profile similar to the model profile discussed later. The real profile is assumed bounded by curves corresponding to the model profile $\pm 50 \%$, and leads to the refraction-angle error given by curve number 6 in figure 5 .

The refraction-angle error due to uncertainties in the observer's altitude $\mathrm{Z}$ can be easily estimated from eq (2T1). Error curve number 7 is the result from assuming an uncertainty in $\mathrm{Z}$ of $\pm 0.1 \mathrm{~km}$.

\subsubsection{Total Refraction-Angle Error}

The total systematic refraction-angle error as a function of elevation angle is assumed to be the linear sum of the component error curves shown in figure 5. The total error is shown in figure 9 and is, like the curves of figure 5, dependent upon atmospheric conditions surrounding the observer's location. This curve is approximated by eq (2T6), which is used by the ETMS to predict refraction-angle error.

As stated in the introduction, a refraction-angle error of less than 3 arcminutes is sufficient to allow the ETMS to commence its measurement procedure. Figure 9 shows that this condition is met for elevation angles in the vicinity of $4^{\circ}$ or larger.

\section{ATMOSPHERIC PROFILE MODELS}

Calculations of the earth-space transmission coefficient to be discussed later are based upon an assumed knowledge of atmospheric temperature, pressure, and water-vapor density profiles. The model profiles used in this report were derived from the 1962 U.S. Standard Atmosphere [9] and are described in this section. 
The solid curved in figure 10 represents the 1962 standard temperature profile to an altitude of $35 \mathrm{~km}$ above sea level. Since very little additional loss occurs above $25 \mathrm{~km}$, the bend in the standard curve at $32 \mathrm{~km}$ is discarded for simplicity. The resulting curve, consisting of the solid curve below and the dashed extension 1 above $32 \mathrm{~km}$, was used in the "exact" integral calculation of the atmospheric transmission coefficient. The curve, consisting of the solid curve below and the dashed extension 2 above $20 \mathrm{~km}$, was used to simplify the calculation of a nonintegral approximation to the molecular oxygen component of the transmission coefficient. Dashed curve 3 is an exponential approximation to the standard curve used to simplify the calculation of the nonintegral approximation to the water-vapor component. All of the resulting curves are uniformly shifted vertically to make the temperature at $\mathrm{Z}$ correspond to local observer conditions.

The solid curve in figure 11 represents the 1962 standard pressure profile. The dashed curve 1 removes a slight bend in the solid curve at $20 \mathrm{~km}$ and, with the solid curve below $20 \mathrm{~km}$, is used in the "exact" integral transmissioncoefficient calculation and in the nonintegral approximation to the corresponding oxygen component. Dashed curve 2 is an exponential approximation to the standard curve used to simplify calculation of the nonintegral approximation to the water-vapor component. These curves are uniformly shifted vertically to reflect local conditions.

The solid curve in figure 12 is the midlatitude water-vapor density profile [10] computed for conditions of the 1962 Standard Atmosphere. Extension 1 which straightens out the standard curve below $16 \mathrm{~km}$ is used with the solid curve below $16 \mathrm{~km}$ in the "exact" integral calculation of the water-vapor component of the transmission coefficient. Dashed curve 2 is an exponential approximation to the standard curve used to simplify calculation of the nonintegral approximation to the water-vapor density component. Both curves are shifted to reflect local conditions.

\section{AN APPROXIMATE TRANSMISSION-COEFFICIENT EQUATION}

Energy radiated by a satellite or radio star and received by an observer on the earth's surface suffers an attenuation $A\left(\theta_{Z}\right)(d B)$ as it traverses the atmosphere to the observer. With reference to figure 1 , this attenuation represents 
the accumulated loss from where the ray enters the atmosphere to the observer at altitude $Z$, with molecular oxygen and water vapor being the significant contributors to this loss [6]. The transmission coefficient $\alpha\left(\theta_{Z}\right)$ corresponding to this attenuation is of primary interest to the observer since it relates the amount of energy entering the atmosphere to the residual he receives. In terms of the attenuation

$$
\alpha\left(\theta_{Z}\right)=10^{-A\left(\theta_{Z}\right) / 10}
$$

The attenuation itself is calculated from the equation [6]

$$
A\left(\theta_{2}\right)=\int\left(\gamma_{1}+\gamma_{2}+\gamma_{3}\right) d l
$$

where $\gamma_{1}, \gamma_{2}$, and $\gamma_{3}$ are absorption coefficients $(\mathrm{dB} / \mathrm{km})$, dl is an infinitesimal arc length along the ray, and the integral is evaluated along the ray from the observer to the point where the ray enters the atmosphere. $\gamma_{1}$ includes the nonresonant absorption arising from the zero-frequency molecular oxygen line and from the absorption due to several natural resonances around $0.5 \mathrm{~cm}$ wavelength. $\gamma_{2}$ arises from the water-vapor absorption line at $1.35 \mathrm{~cm}$, and $\gamma_{3}$ accounts for the water-vapor absorption bands above this line. The integral in eq (4.2) is too time consuming to be performed by the ETMS on a quasi-real-time basis, and therefore nonintegral approximations were derived. The derivation of these approximations is the subject of this section.

Expressions for $\gamma_{1}, \gamma_{2}$, and $\gamma_{3}$ appearing in the literature [6] contain line-width factors in their denominators that, due to their dependence on atmospheric variables, complicate the calculation of $\mathrm{A}\left(\theta_{Z}\right)$. Discarding these factors in the denominators causes little error in the $1 \mathrm{GHz}$ to $10 \mathrm{GHz}$ frequency range of interest in this report. The approximations resulting from discarding these factors are given by eqs (3T3), (3T6), and (3T9) in table 3 with $Z$ equal to zero. They are plotted in figure 13 for T, P, and $\rho$ equal respectively to 293 kelvins, 1013.25 millibars, and $7.75 \mathrm{~g} / \mathrm{m}^{3}$. The corresponding zenith attenuation $\left(\theta_{Z}=90^{\circ}\right)$ as a function of frequency is plotted in figure 14 for 300 kelvins, 1013.25 millibars, and $7.75 \mathrm{~g} / \mathrm{m}^{3}$.

In general, the ray path in figure 1 must be determined before the integral in eq (4.2) can be performed. However, for $\theta_{Z} \geq 3^{\circ}$, this equation can be approximated by 


$$
A\left(\theta_{Z}\right)=\left(\operatorname{Csc} \theta_{Z}\right) \int_{Z}^{\infty}\left(\gamma_{1}+\gamma_{2}+\gamma_{3}\right) d z
$$

where the integral in eq $(4.3)$ is performed along the observer's zenith $\left(\theta_{z}=90^{\circ}\right)$, giving the zenith attenuation. The error accompanying the approximation embodied in eq (4.3) will be discussed later.

Before proceeding to a nonintegral approximation for $A\left(\theta_{Z}\right)$ and $\alpha\left(\theta_{Z}\right)$, it is of interest to consider the error resulting from truncating the upper integral limit in eq (4.3). The effect is shown in figure 15 as a function of the truncation altitude. For example, terminating the integral at $8 \mathrm{~km}$ results in a $10 \%$ error in calculating the zenith attenuation. The graph shows the error to be insignificant for altitudes of $25 \mathrm{~km}$ or greater.

With the line factors removed from the denominators of $\gamma_{1}, \gamma_{2}, \gamma_{3}$ as previously discussed, it is possible to separate the zenith attenuation $A$ into the following form

$$
A=\gamma_{1}(T, P, f) \ell_{1}(Z, T)+\gamma_{2}(T, P, \rho, f) \ell_{2}(Z, T, \rho)+\gamma_{3}(T, P, \rho, f) \ell_{3}(Z, T, \rho)
$$

where $\gamma_{1}, \gamma_{2}$, and $\gamma_{3}$ are ground-level absorption coefficients corresponding to atmospheric conditions prevailing at the observer's location. The arguments $T$, $P$, $P$, and $f$ signify dependence on atmospheric temperature, pressure, water-vapor density, and frequency respectively at the observer's altitude $Z$. $l_{1}, l_{2}, l_{3}$ are scale heights depending upon prevailing conditions. Separation of $A\left(\theta_{Z}\right)$ into the form given by eq (4.4) leads to the following definitions for $l_{1}, l_{2}$, and $l_{3}$

$$
\begin{gathered}
\ell_{1}=\int_{Z}^{\infty}\left(\frac{P(z)}{P}\right)^{2}\left(\frac{T}{T(z)}\right)^{11 / 4} d z \\
\ell_{2}=\int_{Z}^{\infty}\left(\frac{P(z)}{P}\right)\left(\frac{T}{T(z)}\right)^{3} e^{2 \cdot 198\left(\frac{T}{T}-\frac{T_{0}}{T(z)}\right)} \frac{\rho(z)}{\rho} d z \\
\ell_{3}=\int_{Z}^{\infty}\left(\frac{P(z)}{P}\right)\left[\frac{T}{T(z)}\right)^{3 / 2} \frac{\rho(z)}{\rho} d z .
\end{gathered}
$$

$T_{0}$ is equal to 293 kelvins, and the factors appearing under the integral signs originate in the expressions for $\gamma_{1}, \gamma_{2}$, and $\gamma_{3}$ [6]. These factors are not 
independent because the atmospheric variables are interrelated, allowing for the simplifications introduced in the next paragraph.

The ideal gas law [11] and curve 2 of figure 10 lead to the following approximations for $z \leq 11 \mathrm{~km}$ :

$$
\frac{P(z)}{P}=\left(\frac{T(z)}{T}\right)^{5.26}
$$

and for $z>11 \mathrm{~km}$

$$
\frac{P(z)}{P} \doteq \mathrm{e}^{-0.158(z-11)}
$$

These equations result in curve 1 (including the solid line before $20 \mathrm{~km}$ ) in figure 11. When they are used to evaluate $\ell_{1}$ from eq (4.5), eqs (3T3), (3T4), and (3T5) in table 3 result.

Reduction of the integrals in $\ell_{2}$ and $\ell_{3}$ requires that more extensive approximations for $T(z), P(z)$, and $\rho(z)$ be made. Fortunately, the water-vapor density falls off rapidly with altitude requiring an approximate fit to the standard curves for only the first $6 \mathrm{~km}$ altitude. The assumed profiles are curve 3 of figure 10, curve 2 of figure 11, and curve 2 of figure 12. Equations (3T8) and (3T11) in table 3 for $l_{2}$ and $l_{3}$ result from the corresponding reduction of eqs $(4.6)$ and $(4.7)$.

Table 3, then, is a collection of approximate equations used by the ETMS to calculate the atmospheric transmission coefficient $\alpha\left(\theta_{Z}\right)$. Errors associated with these equations are discussed in the following sections.

\subsection{Transmission-Coefficient Errors}

A derivation of the atmospheric transmission-coefficient equations used by the ETMS was outlined in the preceding sections. An estimate of the corresponding systematic error will be outlined in this and succeeding subsections. The error in $\alpha\left(\theta_{z}\right)$ arises from the following sources: (1) use of the nonintegral approximations given in table 3; (2) the nonspherical symmetry of the real atmosphere; (3) uncertainties in the constants appearing in the expression for $\gamma_{1}, \gamma_{2}$, and $\gamma_{3}[6] ;(4)$ uncertainty in the atmospheric temperature profile; (5) uncertainty in the atmospheric pressure profile; (6) uncertainty in the atmospheric water-vapor density profile; (7) uncertainty in the observer's altitude; and (8) uncertainty in the observer's viewing angle $\theta_{Z}$. 
A computer program was written to perform the "exact" calculation of $A\left(\theta_{Z}\right)$ and $\alpha\left(\theta_{Z}\right)$ using eqs $(4.1)$ and (4.2), including the ray-bending equations of section 2 to predict the "exact" ray path. The "exact" calculations used curve 1 of figures 10, 11, and 12. The results of the "exact" calculation were compared with predictions using the equations of table 3. The difference between the "exact" and approximate calculations was assumed to be the error arising from the approximate nature of the table 3 equations. Curve number 1 of figure 16 is the result shown as a function of the angle $\theta_{Z}$.

\subsubsection{Nonspherical Symmetry}

The idealized assumption of spherical atmospheric symmetry yielding eqs (4.2) and (4.3) leads to an error that was estimated in a manner similar to that used for the nonspherical refraction-angle error of section 2. The percentage transmission-coefficient error was assumed to be the same as that case leading to curve 2 of figure 16 .

\subsubsection{Absorption-Coefficient Constants}

The absorption coefficients $\gamma_{1}, \gamma_{2}$, and $\gamma_{3}$ were obtained from the literature [6] and contain constants whose uncertainties are assumed here to be $10 \%$. The corresponding error in $\alpha\left(\theta_{Z}\right)$ is shown as curve 3 in figure 16.

\subsubsection{Temperature, Pressure, and Water-Vapor Density Profiles}

Assumed uncertainties in the atmospheric temperature, pressure, and watervapor density profiles have already been discussed in subsection 2.1.4. These uncertainties were used in a manner similar to those used to establish systematic error bounds on the refraction angle $\tau$. The resulting errors are shown as curves 4,5 , and 6 in figure 16 .

Transmission-coefficient errors due to uncertainties in the observer altitude $Z$ and elevation angle $\theta_{Z}$ were calculated from table 3 equations by assuming $\pm 0.1 \mathrm{~km}$ and $\pm 0.01^{\circ}$ for $z$ and $\theta_{Z}$ respectively. Curves 7 and 8 of figure 16 show these errors. 


\subsubsection{Total Transmission-Coefficient Error}

The total systematic transmission-coefficient error is assumed to be a linear sum of the eight component errors shown in figure 16. The result is shown in figure 17. This curve, like those of figure 16, varies slightly with atmospheric conditions and frequency. Figures 16 and 17 are appropriate to average conditions for the month of May in the vicinity of Washington, D.C., and a frequency of $10 \mathrm{GHz}$. Equation (3T12) in table 3 is an approximation for figure 17 that reflects local conditions in general and is used by the ETMS to calculate the systematic error for $\alpha\left(\theta_{Z}\right)$. This equation implies a $50 \%$ systematic error in the atmospheric loss as calculated from the table 3 equations.

\section{RESULTS AND CONCLUSIONS}

An outline for the derivation of equations used by the ETMS to calculate atmospheric refraction angle and transmission coefficient and their corresponding systematic errors has been presented in sections 2,3 , and 4, leading to the approximations found in tables 2 and 3 . The error components for the refraction angle and transmission coefficient are presented in figures 5 and 16 respectively, with the corresponding total errors (linear sums of the component errors) presented in figures 9 and 17. The equations in both tables apply only to stable, clear weather conditions.

Figure 9 shows that the equations in table 2 can be used to calculate the refraction angle to an error of 3 minutes or less for elevation angles greater than $4^{\circ}$. This accuracy is sufficient for the ETMS to commence its earth-terminal measurement procedures in most geographical locations now in operation.

Equation (3T12) is an approximation for the transmission-coefficient error shown in figure 17, revealing how the error varies with weather conditions through the loss factor " $1-\alpha\left(\theta_{Z}\right)$." This equation implies that the error in the loss itself is approximately $50 \%$, independent of elevation angle, weather (stable) conditions, and frequency (in the $1 \mathrm{GHz}$ to $10 \mathrm{GHz}$ range). 


\section{ACKNOWLEDGMENTS}

The work reviewed in this report represents a small part of the total effort expanded to design and construct an earth-terminal-measurement system for $\mathrm{G} / \mathrm{T}, \mathrm{C} / \mathrm{kT}$, and EIRP measurements. The system was built for the U.S. Army Communications Command at Fort Huachuca, Arizona, whose support is gratefully acknowledged. 


\section{REFERENCES}

[1] Wait, D. F., Satellite earth terminal G/T measurements, Microwave Journal, 20, No. 4 (April 1977).

[2] Daywitt, W. C., Error equations used in the NBS precision G/T measurement system, NBSIR 76-842 (Sept. 1976).

[3] Daywitt, W. C., Error equations used in the NBS earth terminal measurement system, NBSIR 78-869 (Dec. 1977).

[4] Hill, D. A., A survey of earth-to-satellite propagation factors between 2.5 and $275 \mathrm{GHz}$, Published in an Office of Telecommunications Report, OT Report, 74-43 (July 1974).

[5] Longley, A. G., Rice, P. L., Prediction of tropospheric radio transmission loss over irregular terrain: A computer method-1968, ESSA Research Laboratories Technical Report, ERL 79-ITS 67 (July 1968).

[6] Bean, B. R., Dutton, E. J., Radio meteorology, NBS Monograph 92 (March 1966).

[7] Bean, B. R., et al., A world atlas of atmospheric radio refractivity, ESSA Monograph 1 (1966).

[8] Handbook of Chemistry and Physics, Ed. C. D. Hodgman (Chemical Rubber Publishing Co., Cleveland, OH, Feb. 1960).

[9] U.S. Standard Atmosphere, 1962, Prepared under sponsorship of the National Aeronautics and Space Administration, U.S. Air Force and the U.S. Weather Bureau (1962).

[10] Handbook of Geophysics and Space Environments, Ed. S. L. Valley (Air Force Cambridge Research Laboratories, Office of Aerospace Research, U.S. Air Force, 1965).

[11] McIntosh, D. H., and Thom, A. S., Essentials of Meteorology (SpringerVerlag, New York, Inc., 1972). 


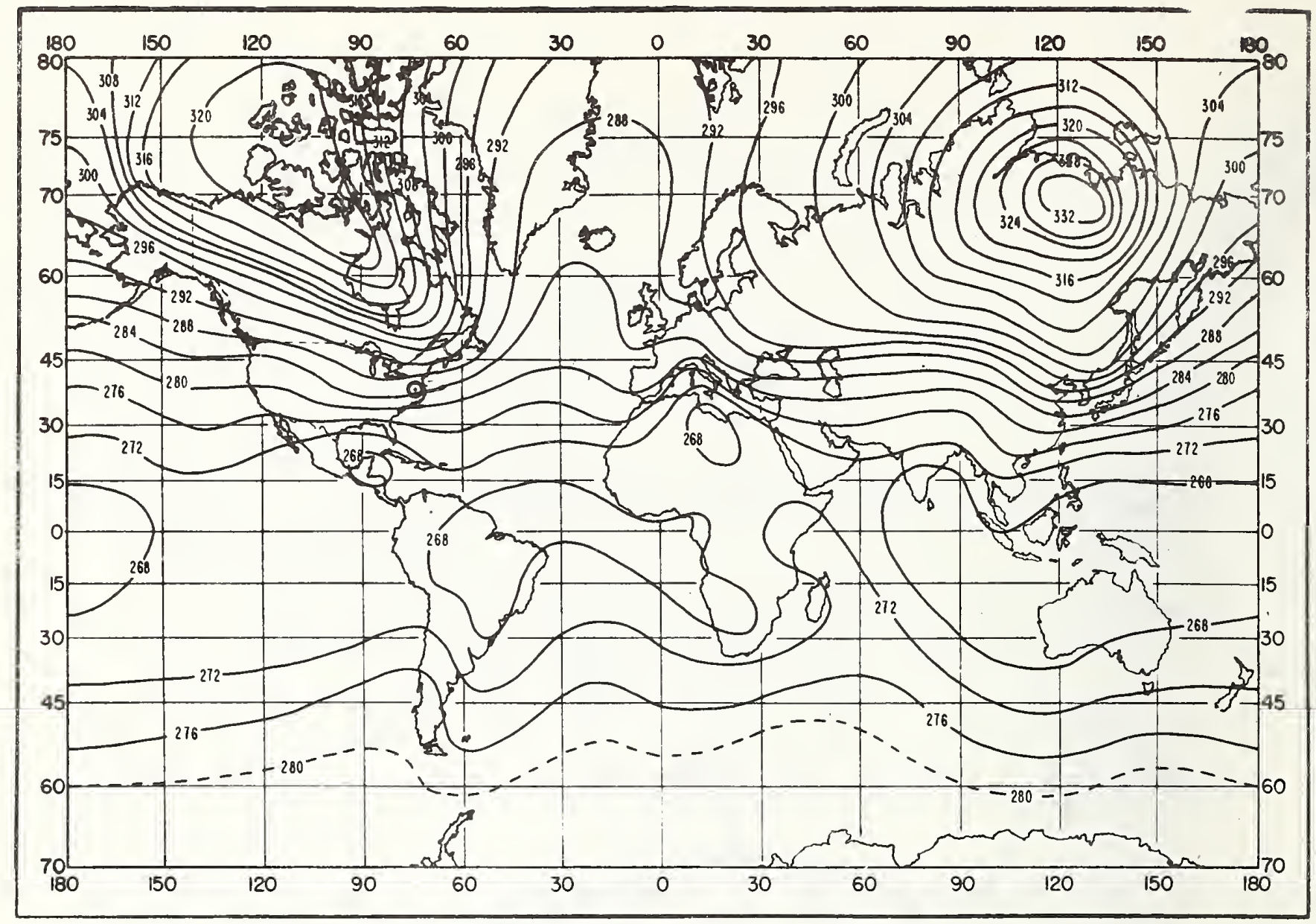

Figure 2. World maps of the mean sea-level dry term $D_{0}$ and wet term $W_{0}$ for May (from Bean, et a1. [7]).

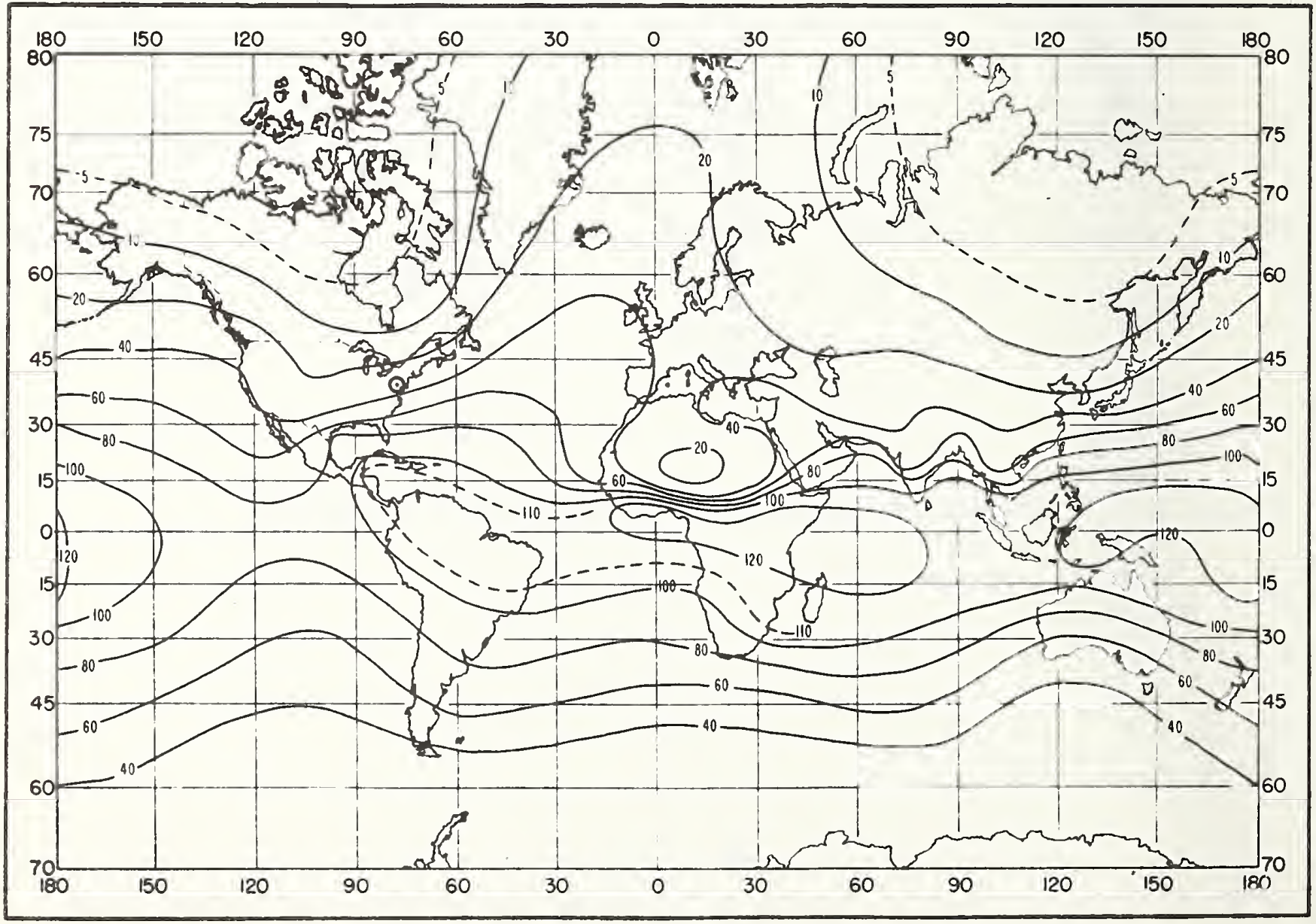




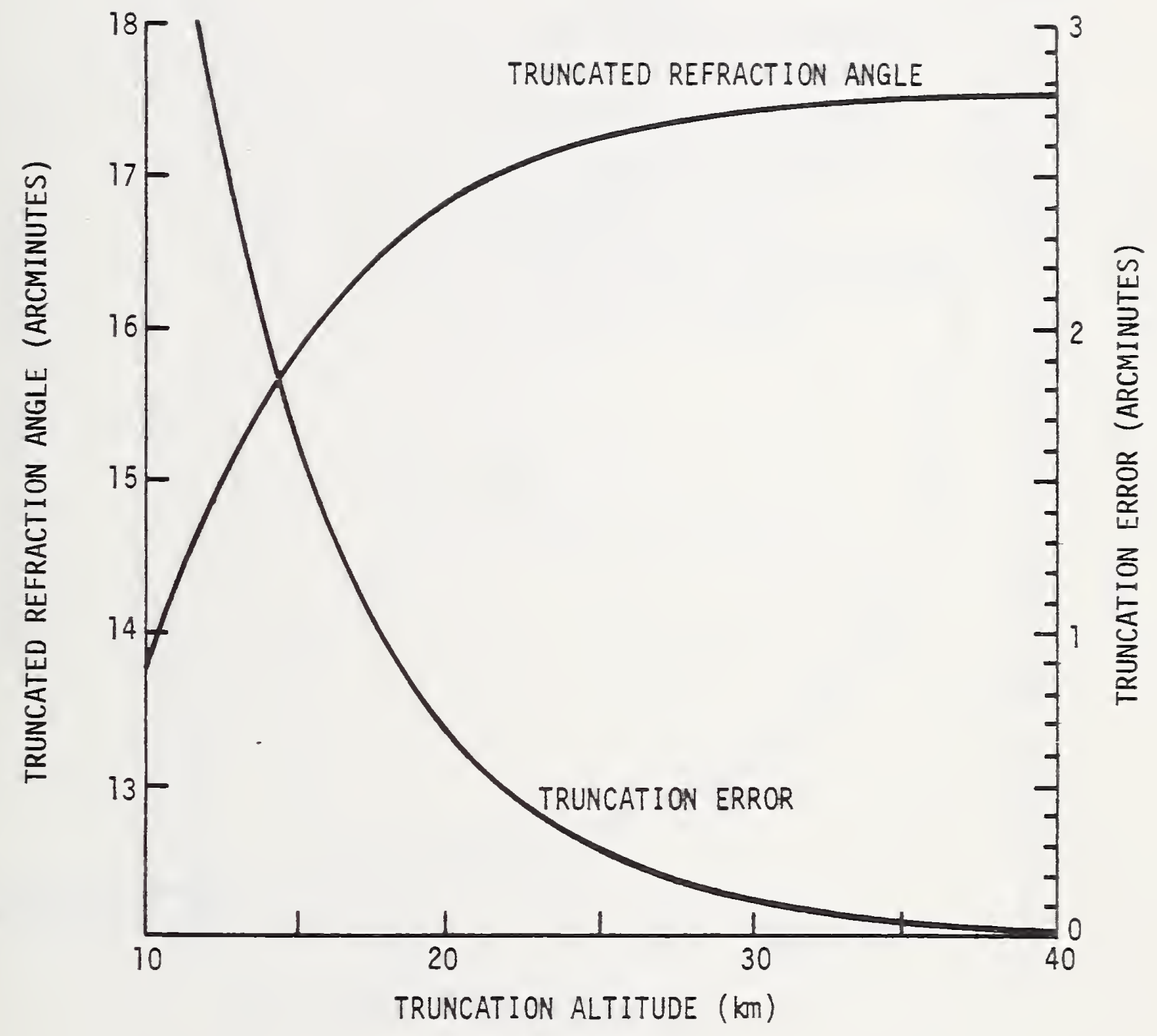

Figure 3. Truncated refraction angle and truncation error versus truncation altitutde at a $3^{\circ}$ elevation angle. 


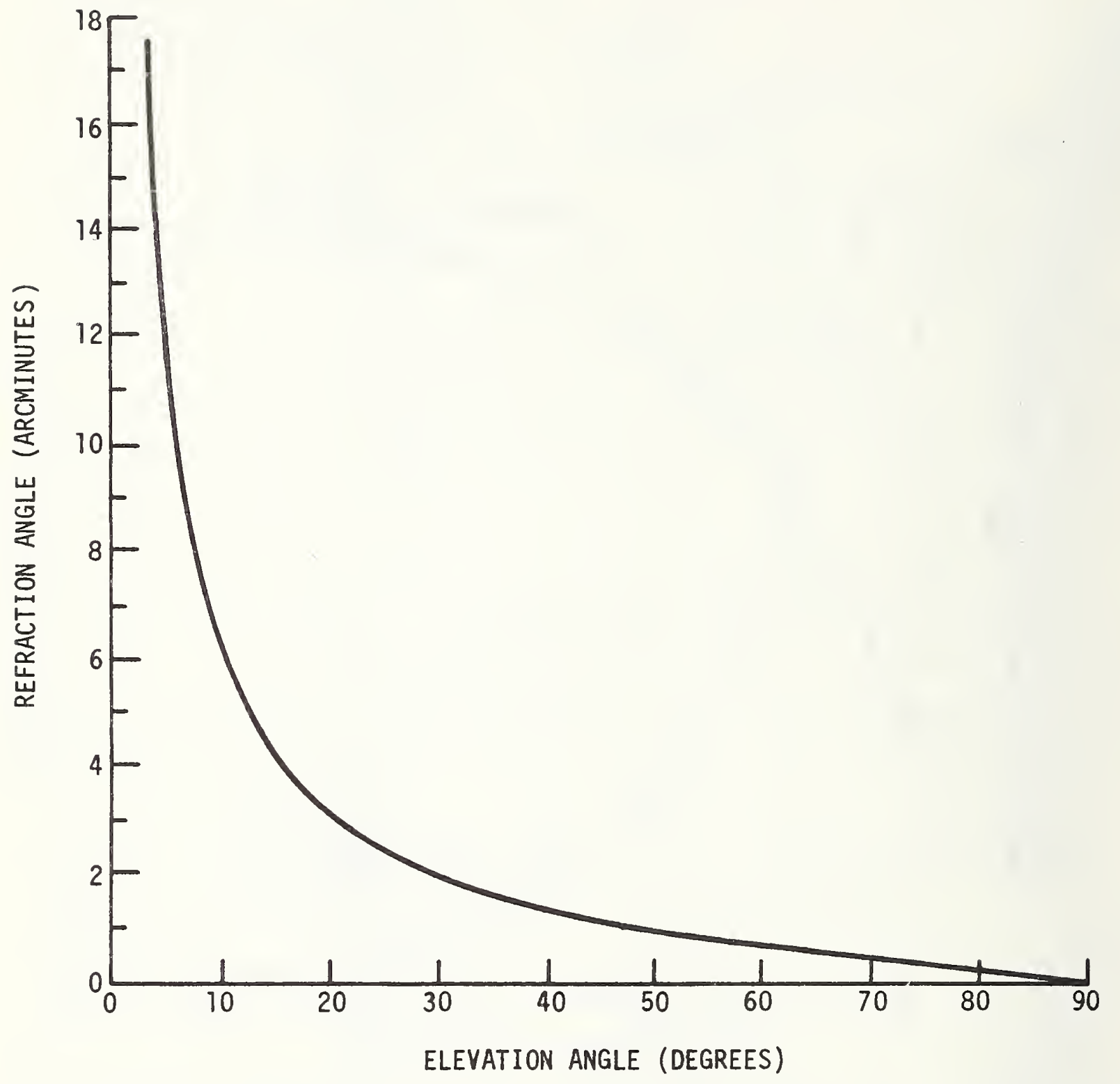

Figure 4. Average May refraction angle for Washington, D.C. 


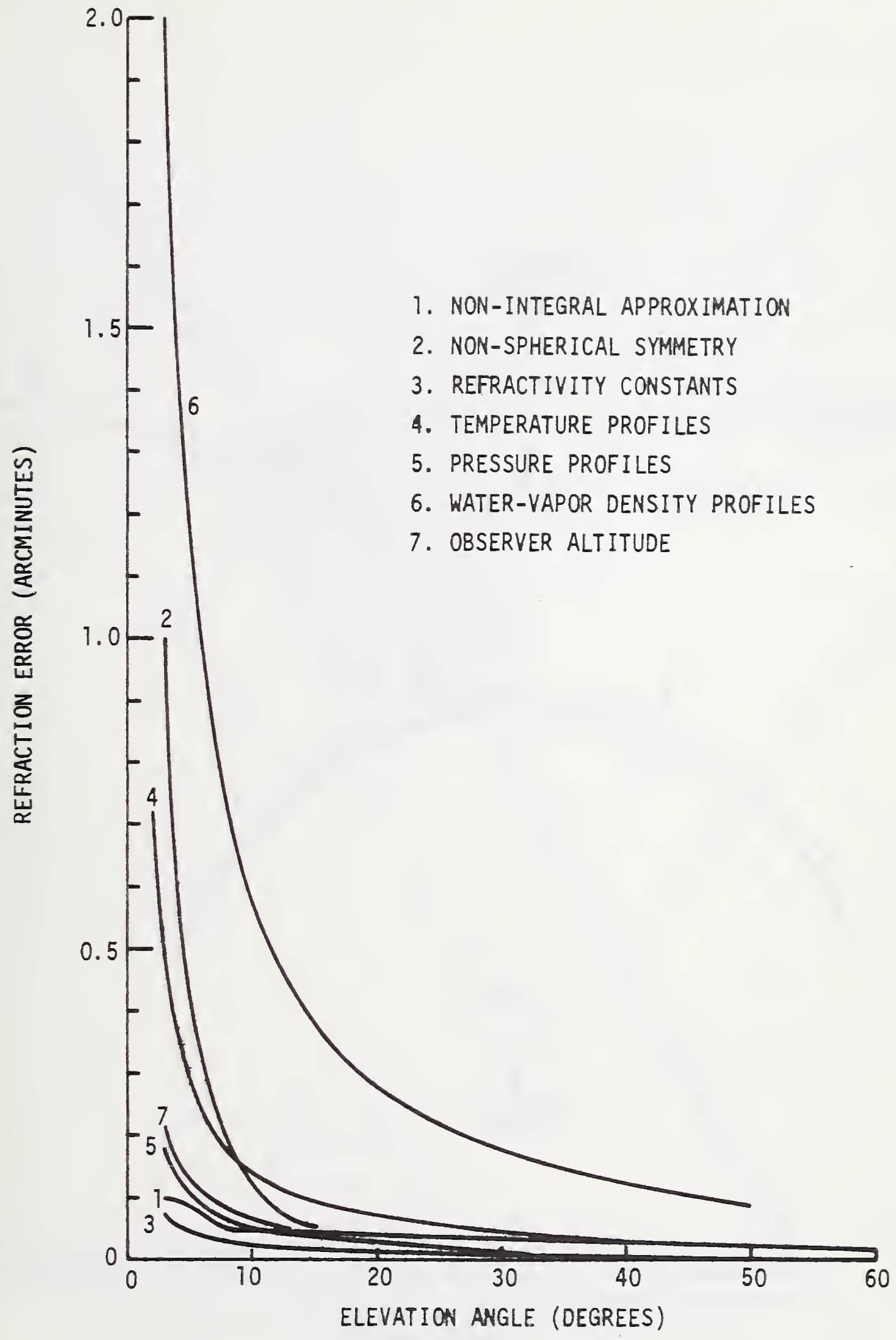

Figure 5. Systematic error components for the refraction angle. 


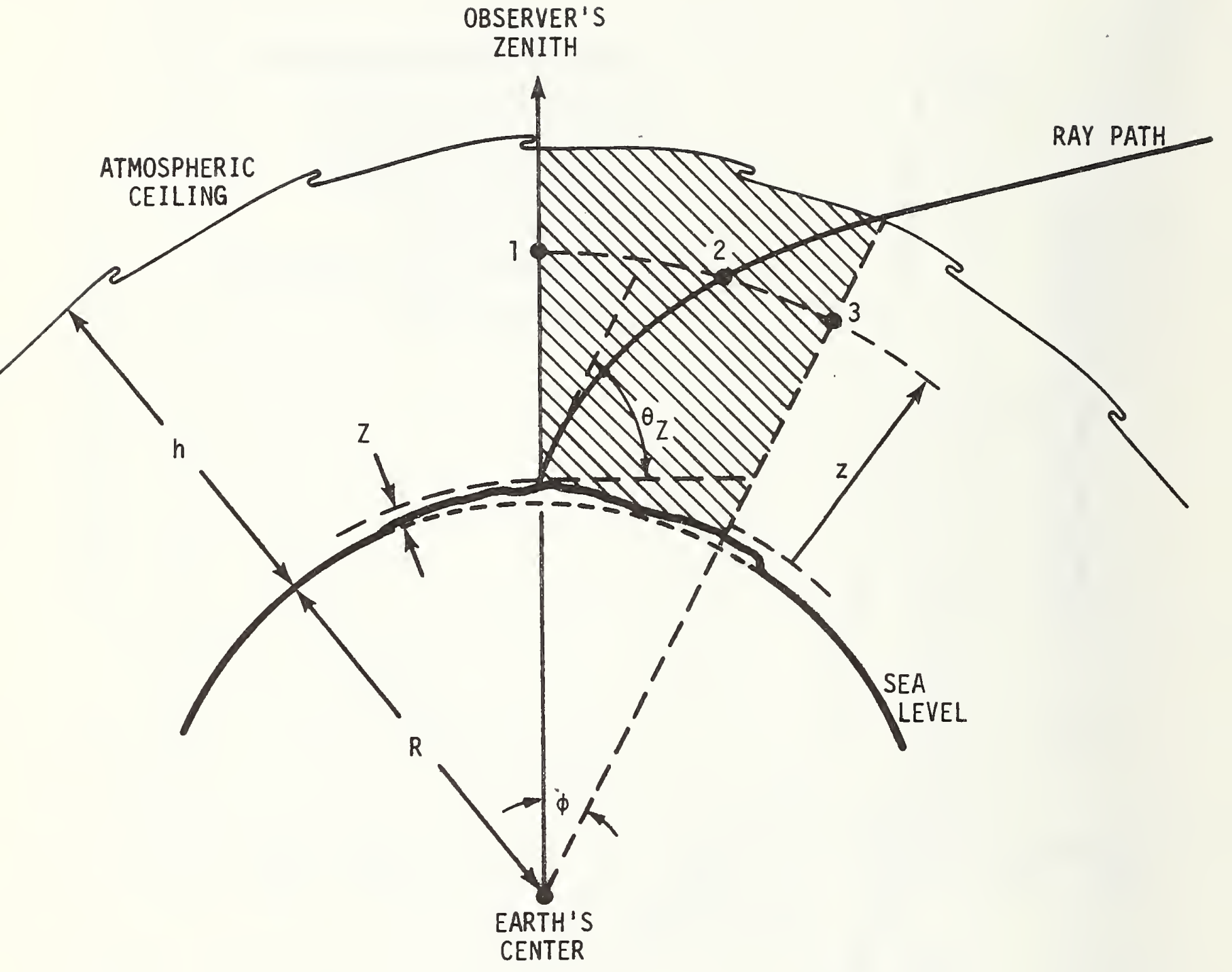

Figure 6.

Geometrical idealization of the earth's atmosphere showing that portion (shaded) in the vicinity of the observer of interest in determining ray bending. 


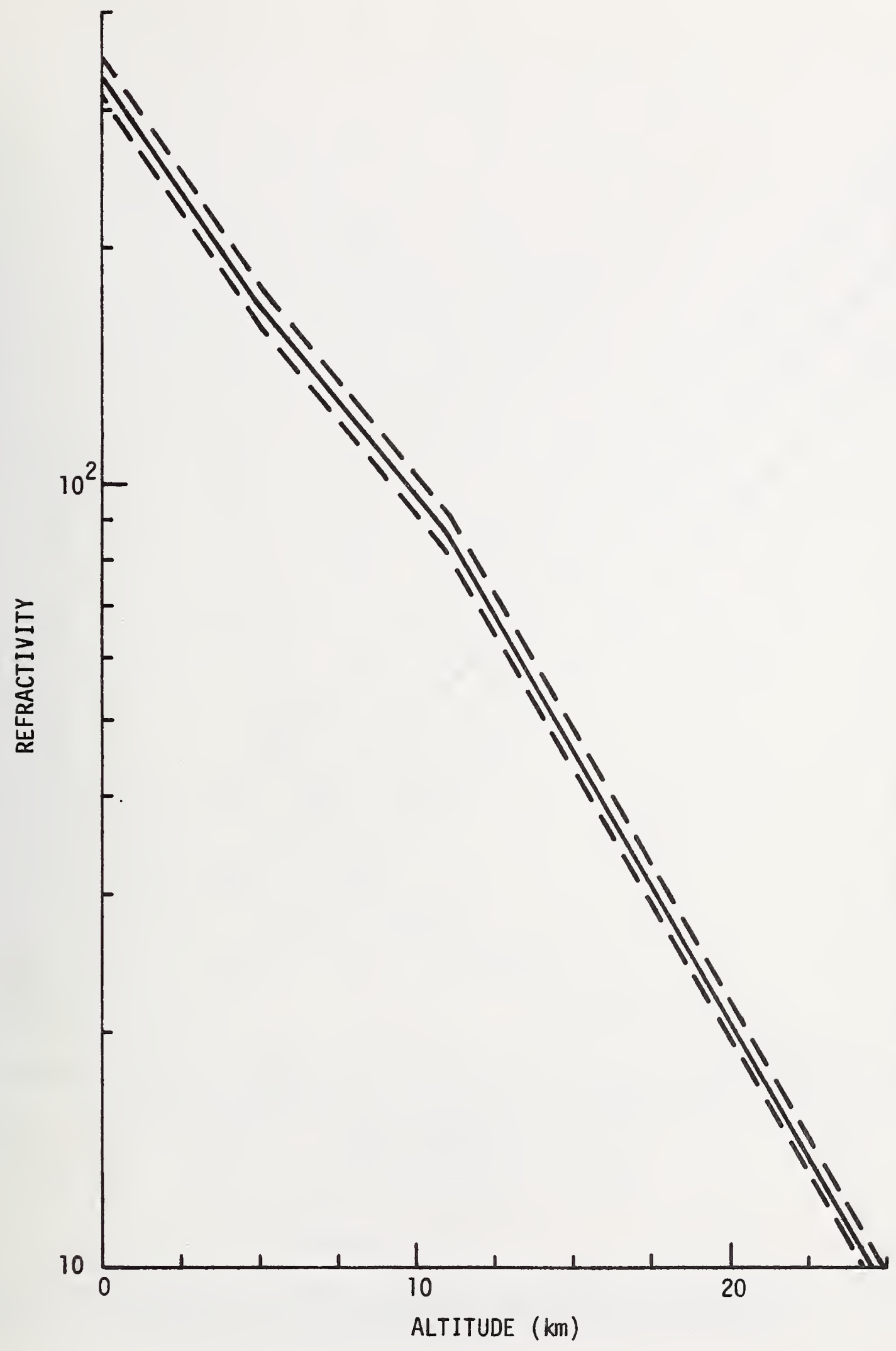

Figure 7. Average May refractivity profile for Washington, D.C., showing that "area" in which the real profile is assumed to lie. 


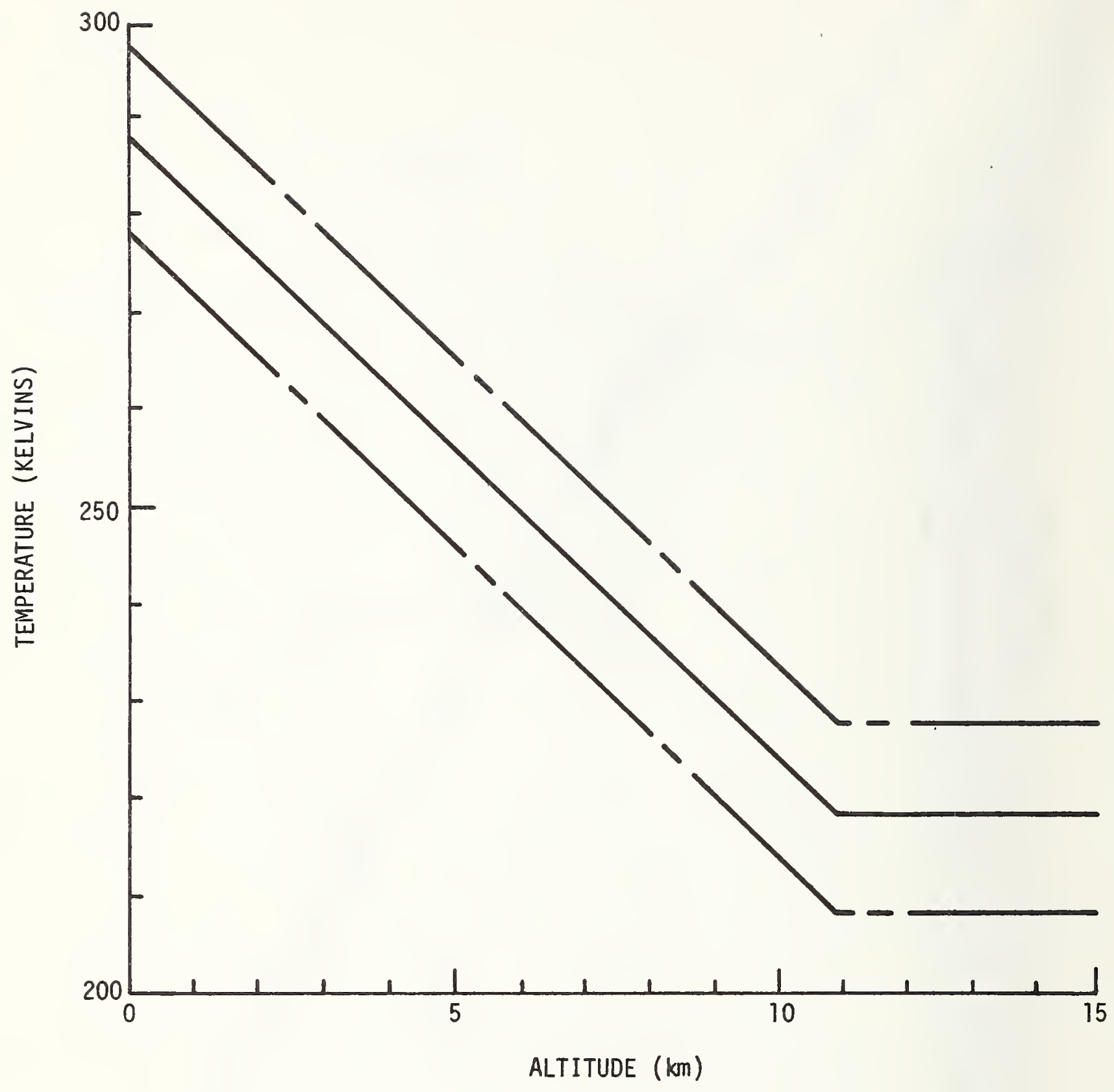

Figure 8 . A portion of the 1962 U.S. standard temperature profile showing that "area" in which the real profile is assumed to lie. 


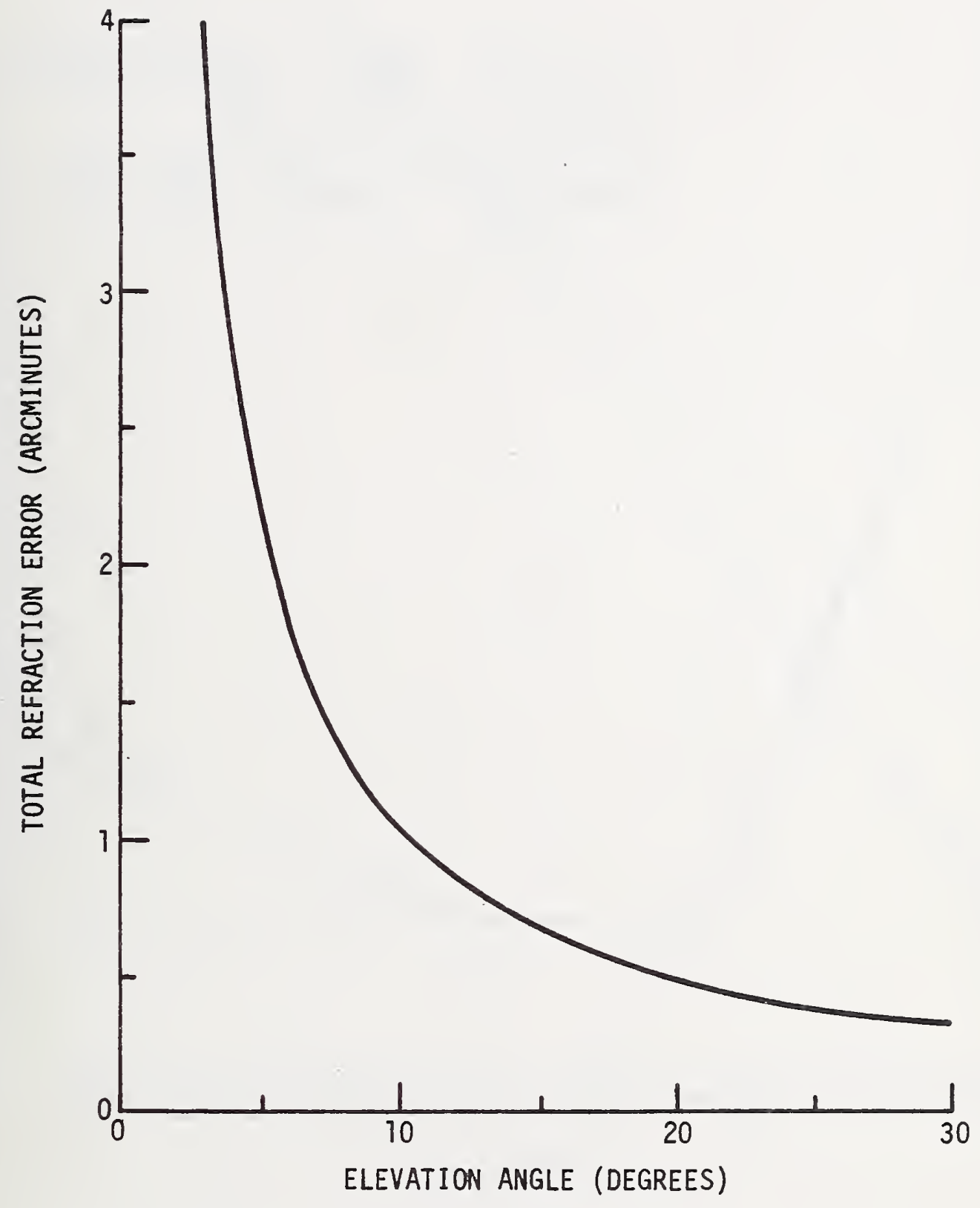

Figure 9. Total systematic refraction-angle error. 


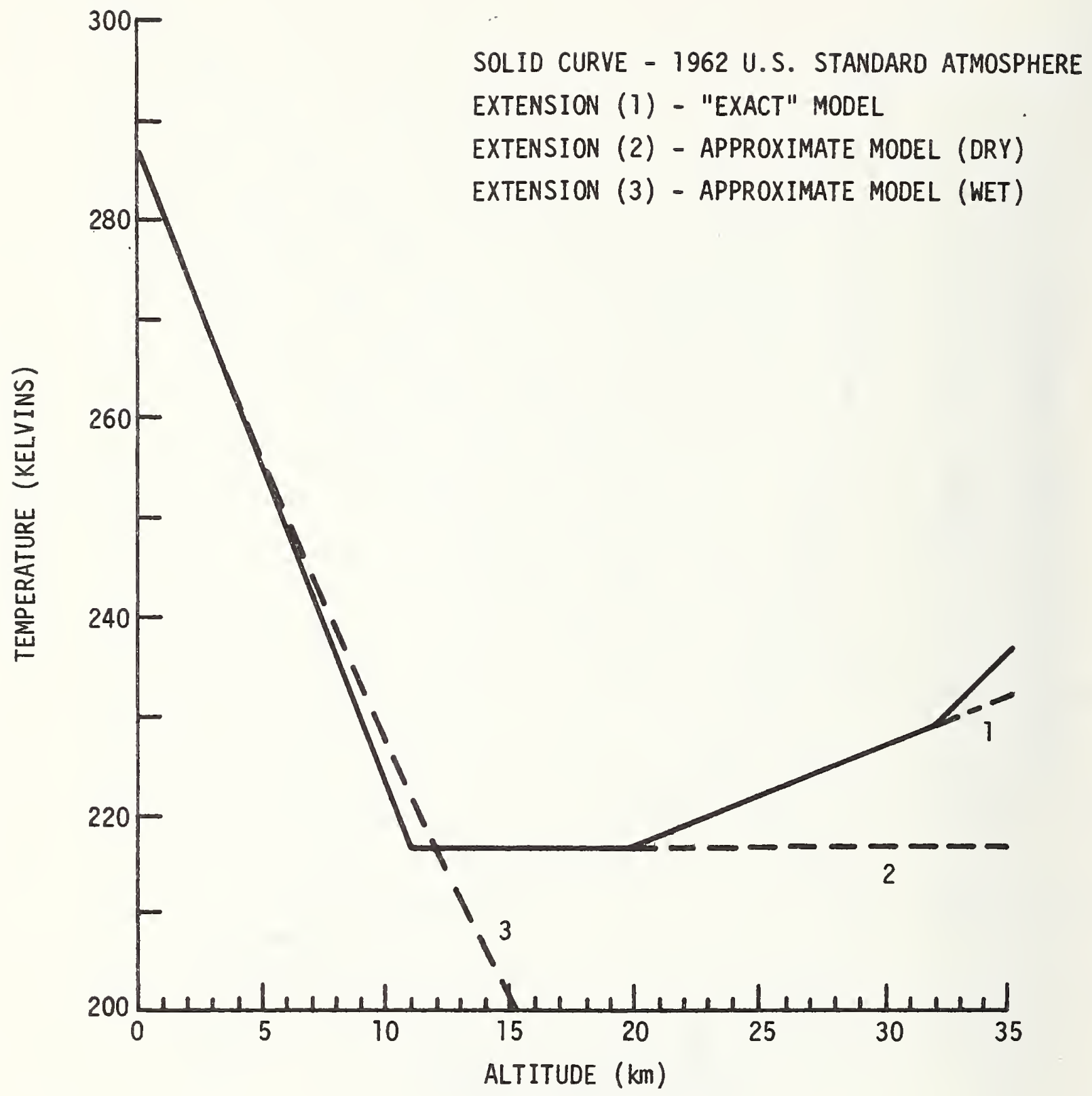

Figure 10. A portion of the 1962 U.S. standard atmospheric temperature profile showing the three approximations (dashed curves) used in the text. 


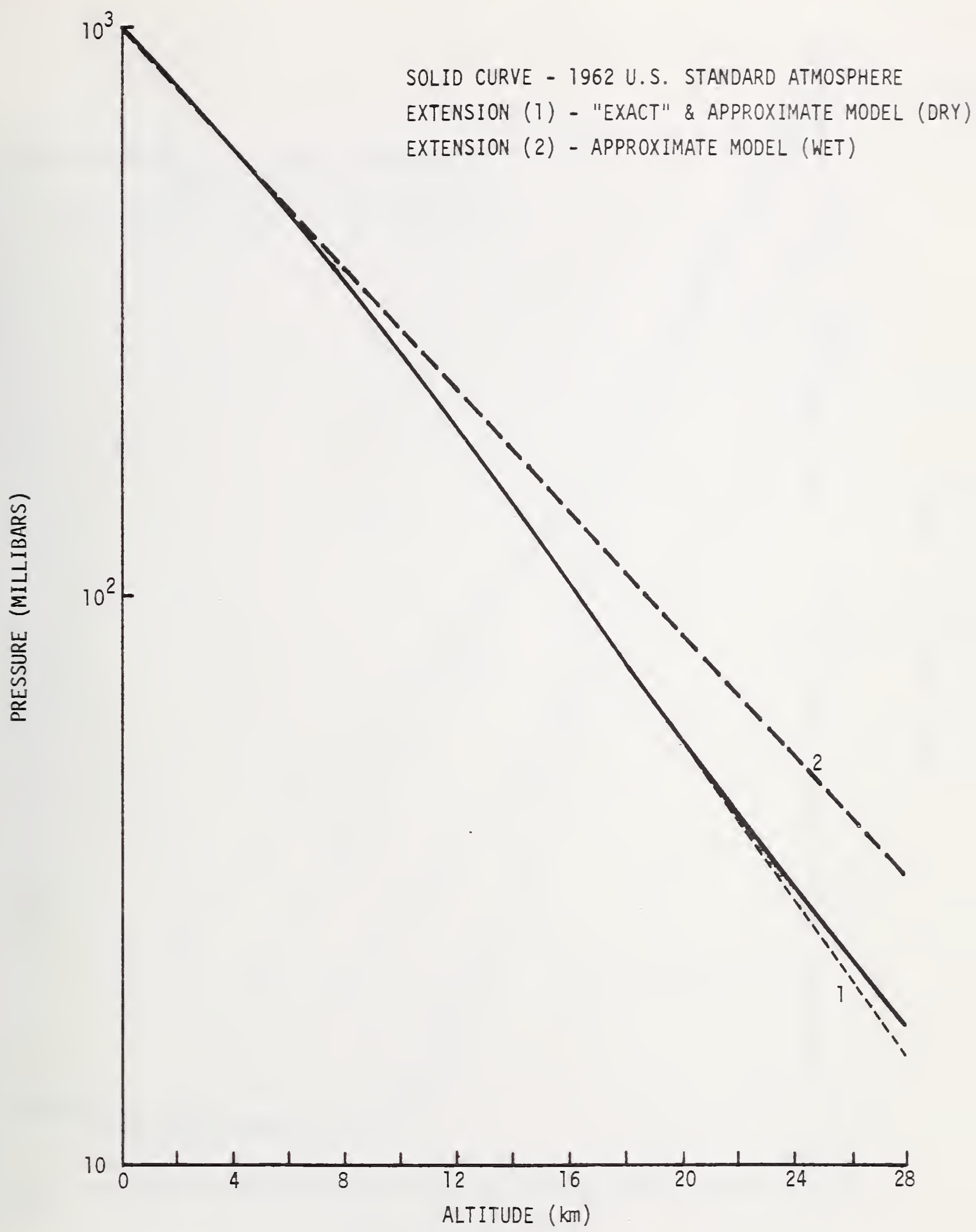

Figure 11. A portion of the 1962 standard pressure profile showing the two approximations (dashed curves) used in the text. 


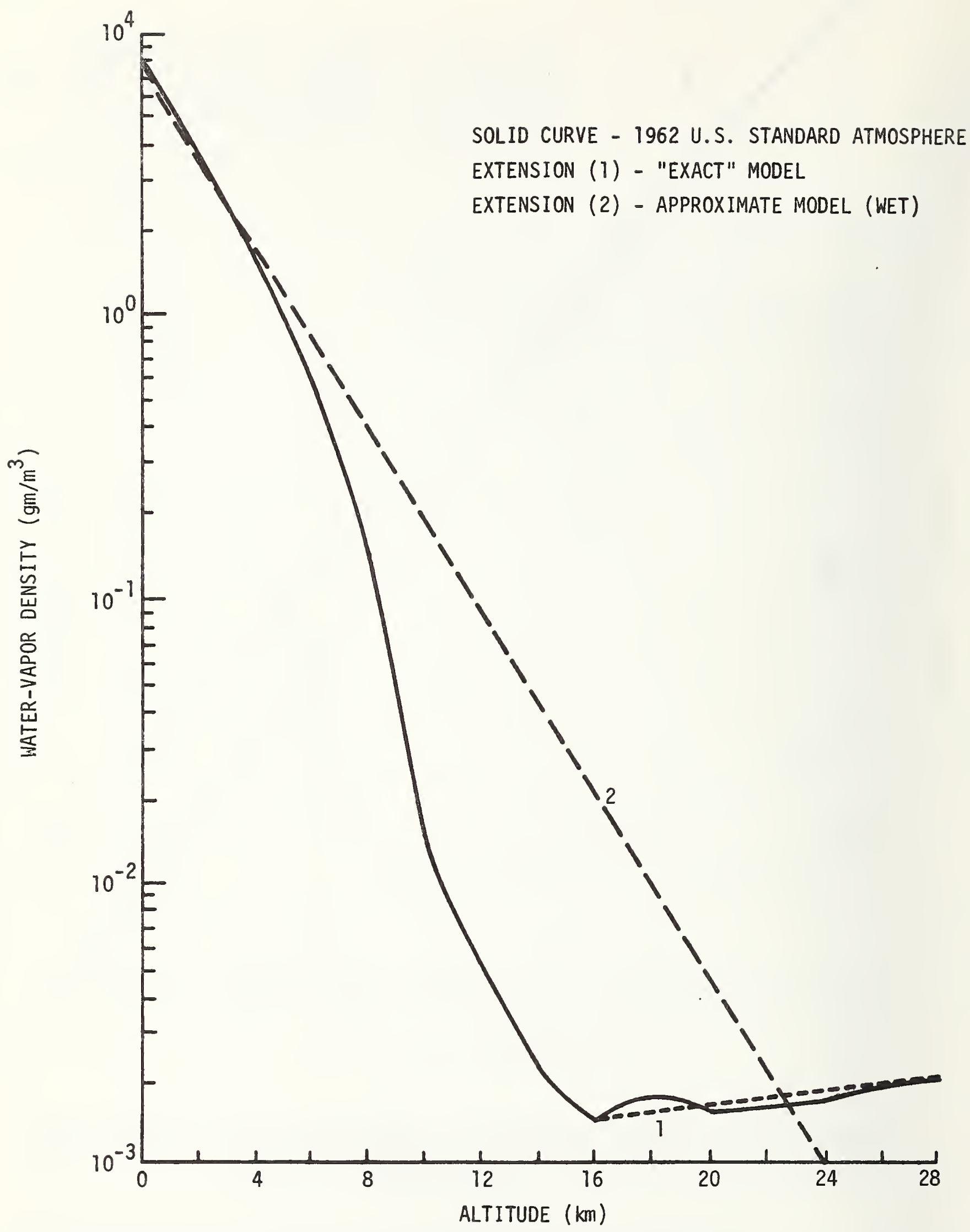

Figure 12. A portion of the 1962 U.S. standard water-vapor density profile showing the two approximations (dashed curves) used in the text. 


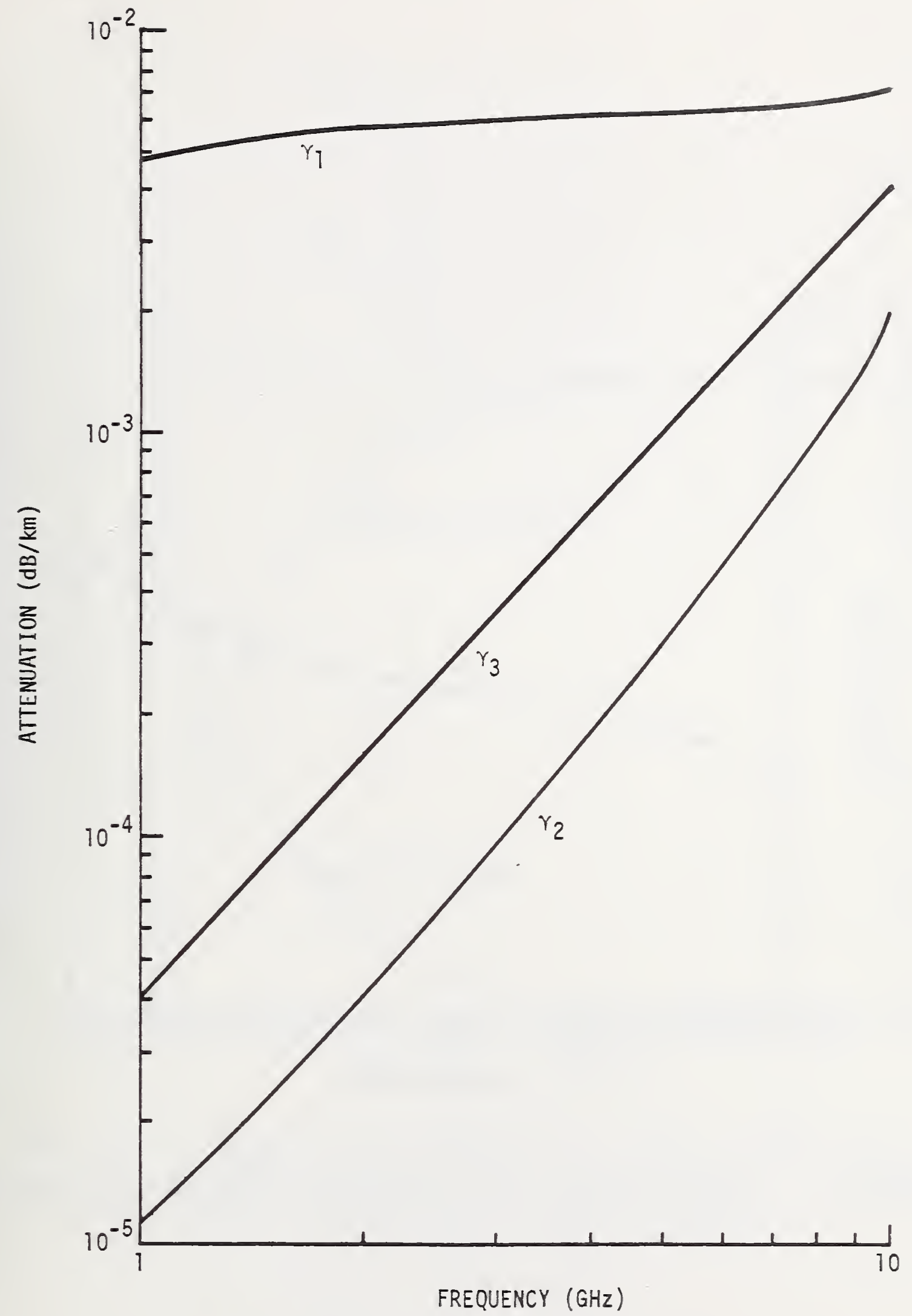

Figure 13. Molecular oxygen and water-vapor absorption coefficients verşus frequency (for 293 kelvins, 1013.25 millibars, and $7.75 \mathrm{~g} / \mathrm{m}^{3}$ ). 


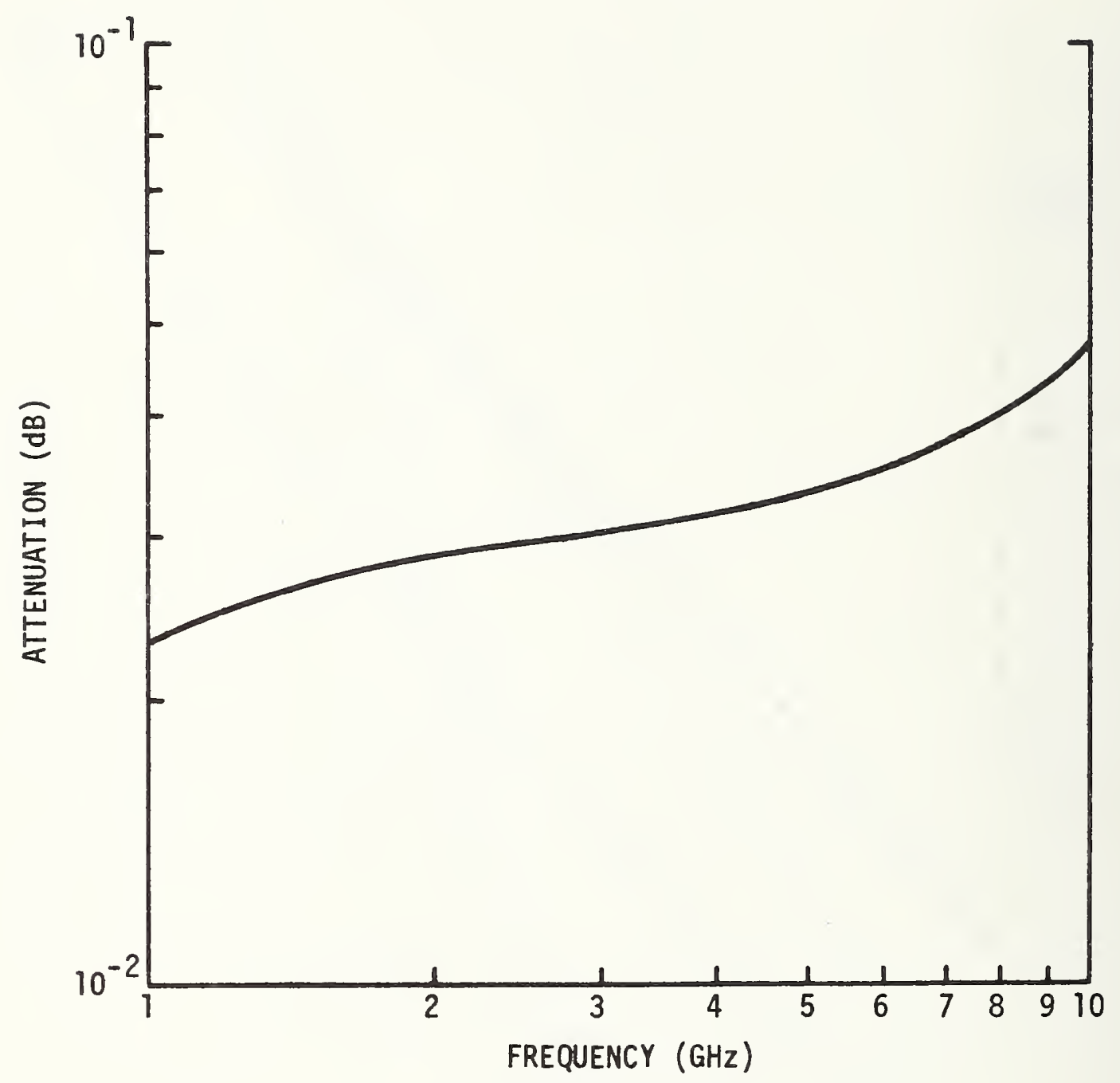

Figure 14. Zenith attenuation due to molecular oxygen and water vapor vȩrsus frequency (for 300 kelvins, 1013.25 millibars, and $7.75 \mathrm{~g} / \mathrm{m}^{3}$ ). 


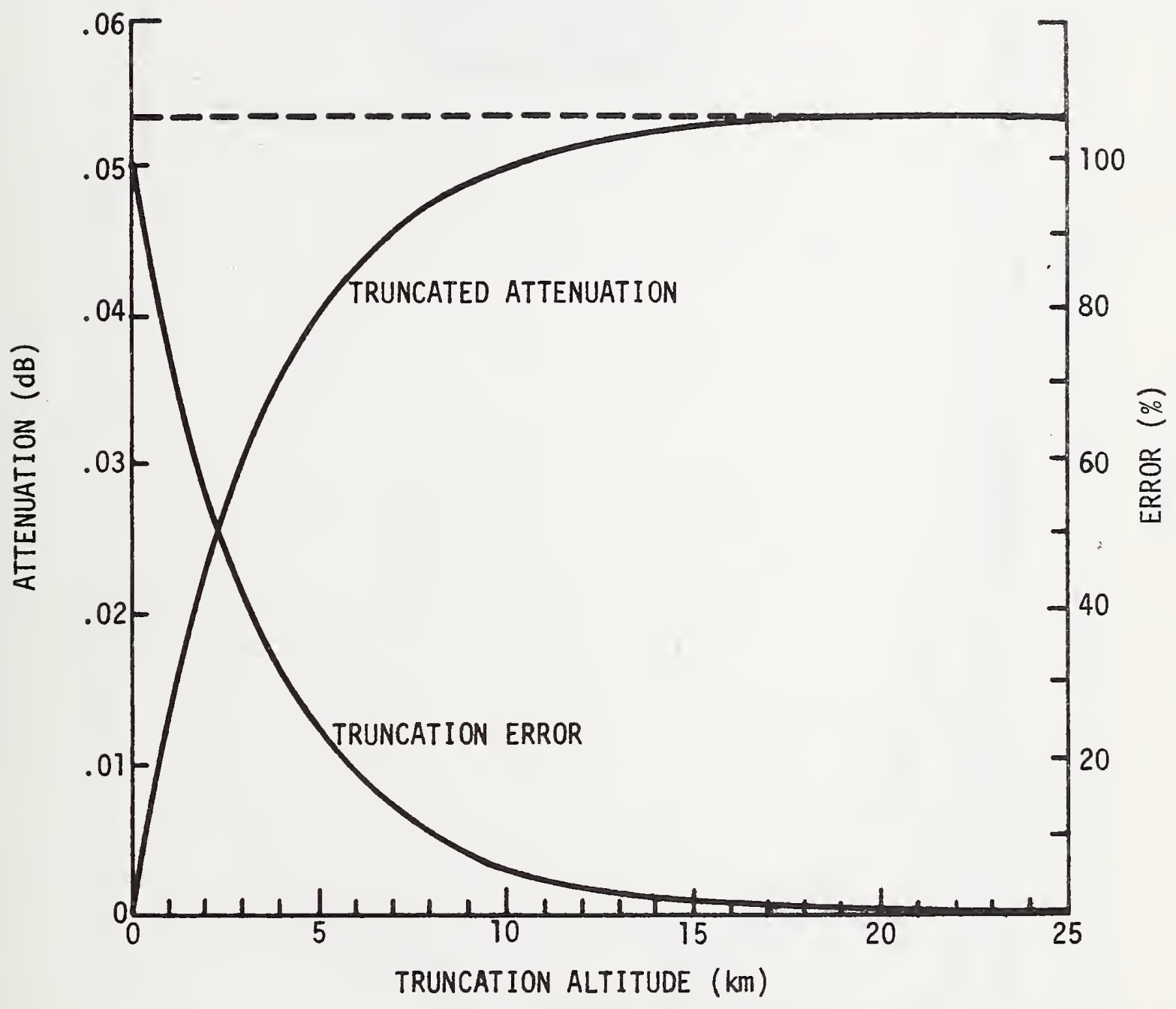

Figure 15. Truncated zenith attenuation and truncation error versus truncation altitude (at $10 \mathrm{GHz}$ for Washington, D.C., in May). 


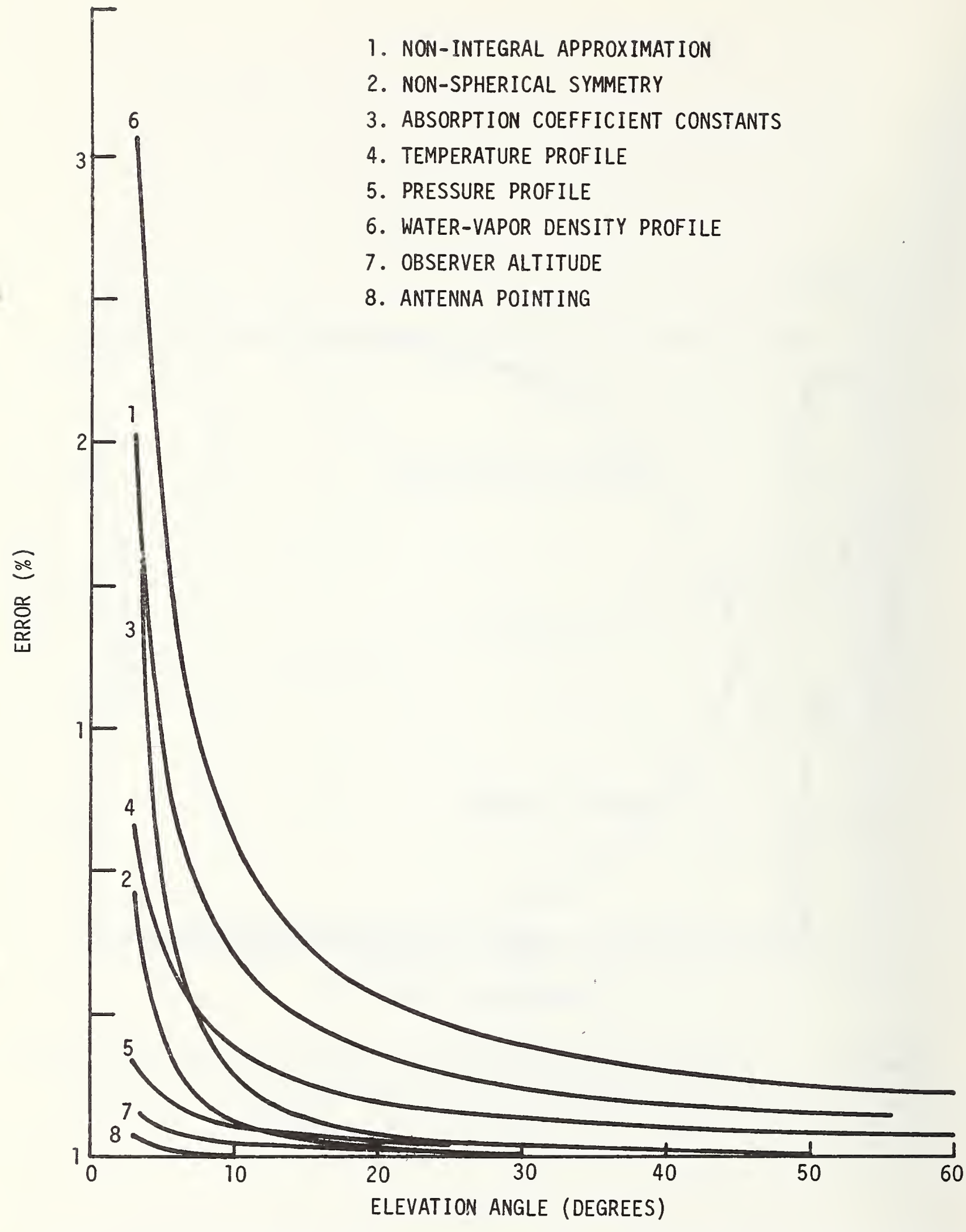

Figure 16. Systematic error components for the transmission coefficient (at $10 \mathrm{GHz}$ for Washington, D.C., in May). 


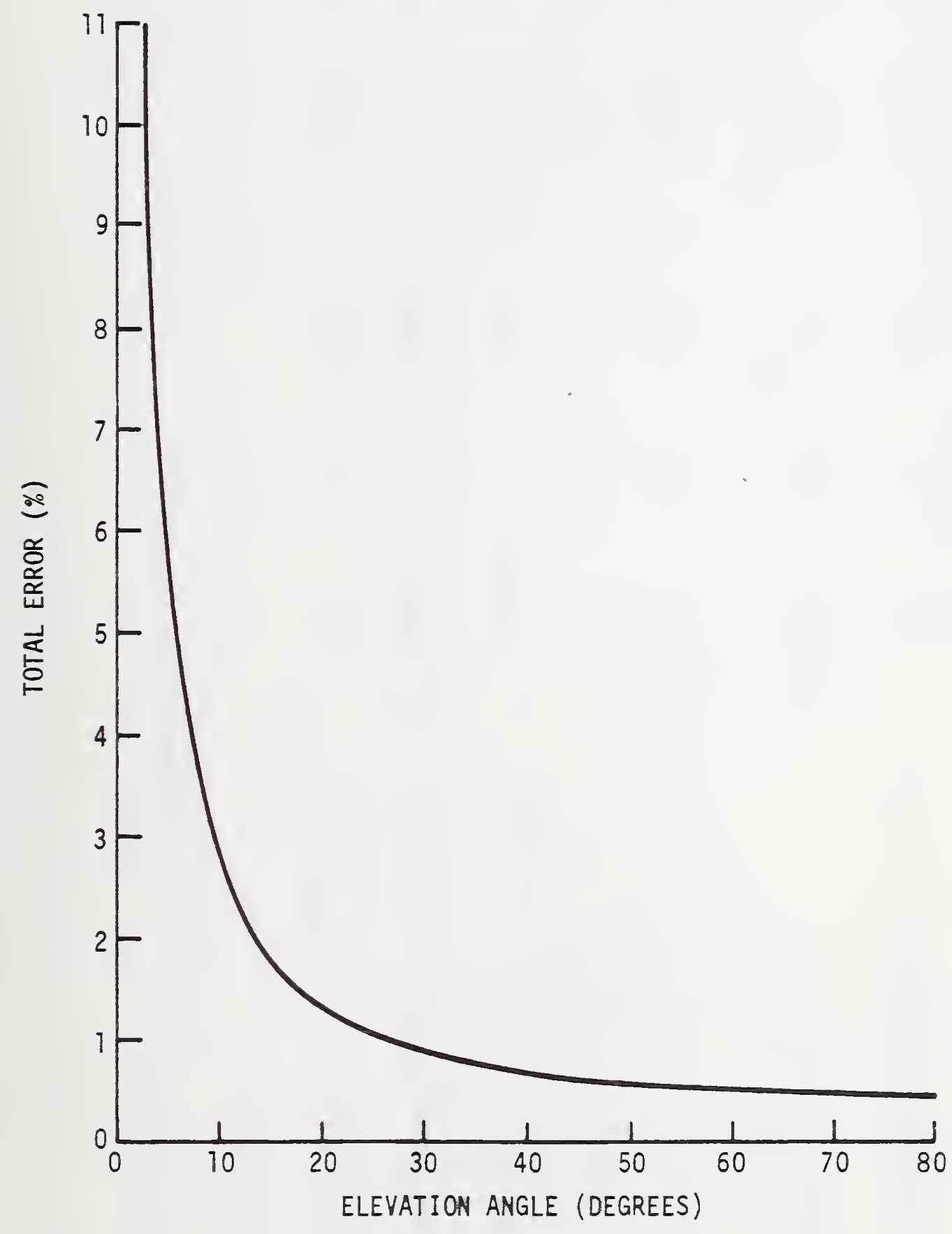

Figure 17. Total systematic transmission-coefficient error (at $10 \mathrm{GHz}$ for Washington, D.C., in May). 


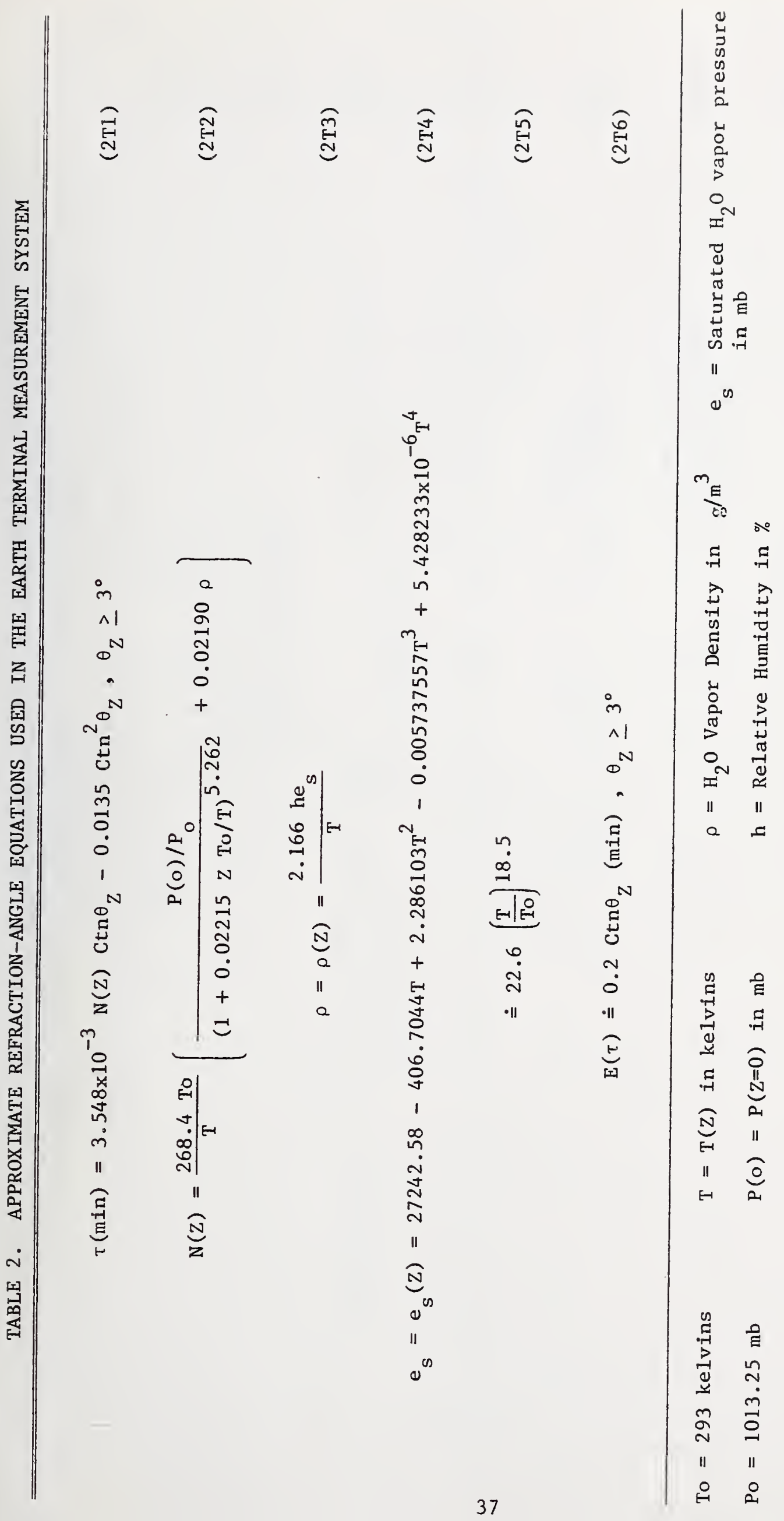


产 気

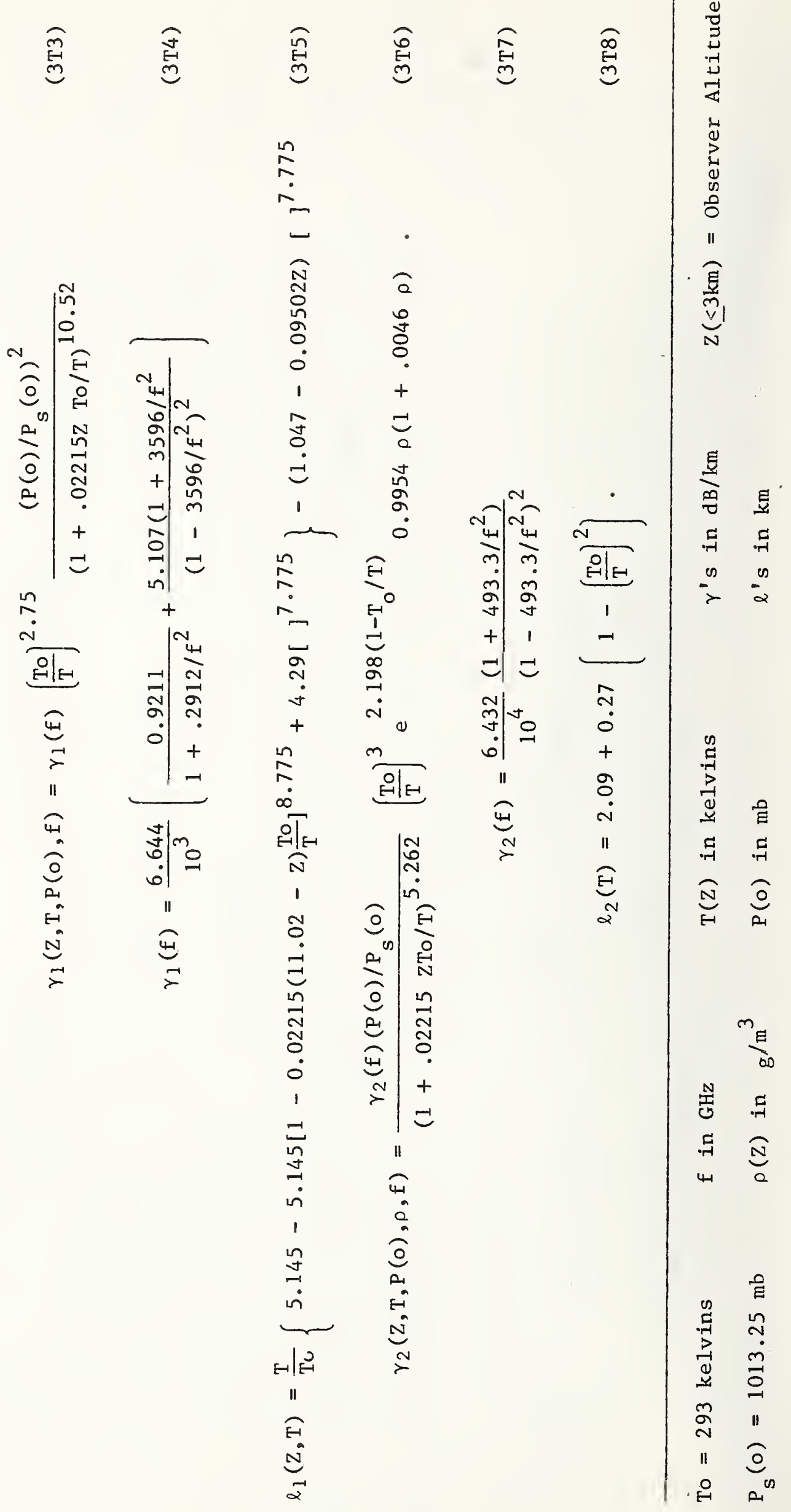


흘

产

商

言

$\stackrel{\text { จิ }}{\cdots}$

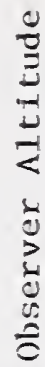

$\frac{\text { ह }}{\text { vै }}$

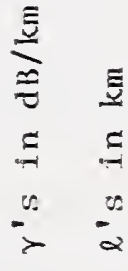

कิ

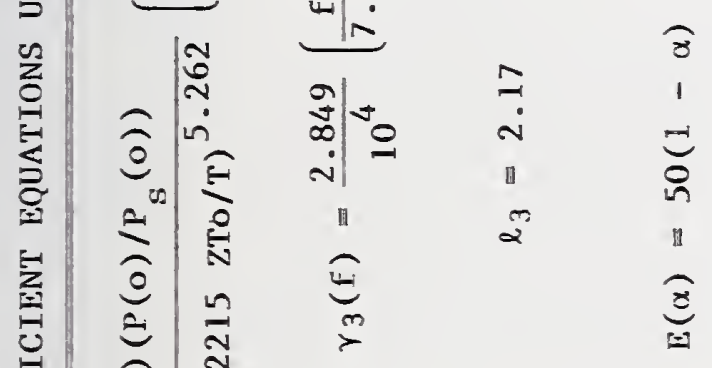

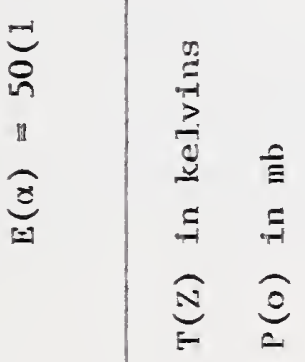

告

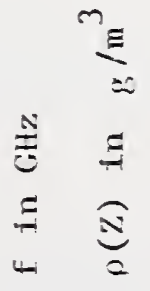

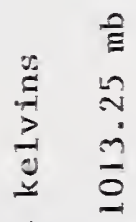

ล 11

i) 


\begin{tabular}{|c|c|c|c|}
\hline $\begin{array}{l}\text { U.S. DEPT. OF COMM. } \\
\text { BIBLIOGRAPHIC DATA } \\
\text { SHEET }\end{array}$ & $\begin{array}{l}\text { 1. PUBLICATION OR REPORT NO. } \\
\text { NBSIR 78-883 }\end{array}$ & $\begin{array}{l}\text { 2. Gov't Accession } \\
\text { No. }\end{array}$ & 3. Recipient's Accession No. \\
\hline \multirow{2}{*}{\multicolumn{3}{|c|}{$\begin{array}{l}\text { 4. TITLE AND SUBTITLE } \\
\text { Atmospheric Propagation Equations Used in the NBS Earth } \\
\text { Terminal Measurement System }\end{array}$}} & $\begin{array}{l}\text { 5. Publication Date } \\
\text { April } 1978\end{array}$ \\
\hline & & & $\begin{array}{l}\text { 6. Performing Organization Code } \\
276.05\end{array}$ \\
\hline \multicolumn{3}{|l|}{$\begin{array}{l}\text { 7. AUTHOR(S) } \\
\text { W. C. Daywitt }\end{array}$} & 8. Performing Organ. Report No. \\
\hline \multirow{2}{*}{\multicolumn{3}{|c|}{$\begin{array}{l}\text { 9. PERFORMING ORGANIZATION NAME AND ADDRESS } \\
\text { NATIONAL BUREAU OF STANDARDS } \\
\text { DEPARTMENT OF COMMERCE } \\
\text { Washington, D.C. } 20234\end{array}$}} & $\begin{array}{l}\text { 10. Project/Task/Work Unit No. } \\
2765266\end{array}$ \\
\hline & & & 11. Contract/Grant No. \\
\hline \multirow{2}{*}{\multicolumn{3}{|c|}{$\begin{array}{l}\text { 12. Sponsoring Organization Name and Complete Address (Street, City, State, ZIP) } \\
\text { Same as } \# 9 \text {. }\end{array}$}} & $\begin{array}{l}\text { 13. Type of Report \& Period } \\
\text { Covered }\end{array}$ \\
\hline & & & 14. Sponsoring Agency Code \\
\hline
\end{tabular}

16. ABSTRACT (A 200-word or less factual summary of most significant information. If document includes a significant bibliography or literature survey, mention it here.)

A derivation of equations for approximating the atmospheric refraction angle and transmission coefficient is outlined. The approximations apply in the $1 \mathrm{GHz}$ to $10 \mathrm{GHz}$ frequency range and are accompanied by systematic error estimates. They are used in the NBS Earth Terminal Measurement System for quasi-rea1-time calculations concerned with the measurement of earth-terminal gain-to-noise-temperature ratio $(\mathrm{G} / \mathrm{T})$, satellite effective isotropic radiated power (EIRP), and downlink carrier-to-noise-density ratio $(\mathrm{C} / \mathrm{kT})$.

17. KEY WORDS (six to twelve entries; alphabetical order; capitalize only the first letter of the first key word unless a proper name; separated by semicolons) Atmosphere; downlink carrier-to-noise-density ratio (C/kT); satellite effective isotropic radiated power (EIRP); error analysis; earth-terminal gain-to-noise-temperature ratio (G/T); refraction angle; satellite communications; transmission coefficient.

\begin{tabular}{|c|c|c|}
\hline $\begin{array}{l}\text { 18. AVAILABILITY Unlimited } \\
\square \text { For Official Distribution. Do Not Release to NTIS }\end{array}$ & $\begin{array}{l}\text { 19. SECURITY CLASS } \\
\text { (THIS REPURT) } \\
\text { UNCL ASSIFIED }\end{array}$ & $\begin{array}{l}\text { 21. NO. OF PAGES } \\
45\end{array}$ \\
\hline $\begin{array}{l}\square \text { Order From Sup. of Doc., U.S. Government Printing Office } \\
\text { Washington, D.C. } 20402, \text { SD Cat. No.C13 }\end{array}$ & $\begin{array}{l}\text { 20. SECURITY CLASS } \\
\text { (THIS PAGE) }\end{array}$ & 22. Price \\
\hline $\begin{array}{l}\text { X] Order From National Technical Information Service (NTIS) } \\
\text { Springfield, Virginia } 22151\end{array}$ & UNCLASSIFIED & $\$ 4.50$ \\
\hline
\end{tabular}

